UNIVERSIDADE DE BRASÍLIA

FACULDADE DE TECNOLOGIA

DEPARTAMENTO DE ENGENHARIA ELÉTRICA

\title{
UTILIZAÇÃO DE MATRIZ SENSIBILIDADE E PROGRAMAÇÃO LINEAR PARA CORRIGIR OS NÍVEIS DE TENSÃO E OTIMIZAR A ALOCAÇÃO DE REATIVOS EM SISTEMAS DE POTÊNCIA
}

MARCOS ANTONIO PAES REZENDE

ORIENTADORA: ALESSANDRA MACEDO DE SOUZA

TRABALHO DE CONCLUSÃO DE CURSO DE ENGENHARIA ELÉTRICA

BRASÍLIA/DF: NOVEMBRO - 2008 
UNIVERSIDADE DE BRASÍLIA

FACULDADE DE TECNOLOGIA

DEPARTAMENTO DE ENGENHARIA ELÉTRICA

\begin{abstract}
UTILIZAÇÃO DE MATRIZ SENSIBILIDADE E PROGRAMAÇÃO LINEAR PARA CORRIGIR OS NÍVEIS DE TENSÃO E OTIMIZAR A ALOCAÇÃO DE REATIVOS EM SISTEMAS DE POTÊNCIA
\end{abstract}

MARCOS ANTONIO PAES REZENDE

TRABALHO SUBMETIDO AO DEPARTAMENTO DE ENGENHARIA ELÉTRICA DA FACULDADE DE TECNOLOGIA DA UNIVERSIDADE DE BRASÍLIA COMO PARTE DOS REQUISITOS NECESSÁRIOS PARA A OBTENÇÃO DO GRAU DE ENGENHEIRO ELETRICISTA.

APROVADA POR:

Prof ${ }^{\mathrm{a}}$ Alessandra Macedo de Souza, Dra (ENE-UnB) (Orientadora)

Prof. Francisco Damasceno Freitas, Dr (ENE-UnB) (Examinador Interno)

Prof. Luis Filomeno de Jesus Fernandes, Dr (Examinador Externo)

BRASÍLIA/DF, 14 DE NOVEMBRO DE 2008 
FICHA CATALOGRÁFICA

REZENDE, MARCOS ANTONIO PAES

Utilização de matriz sensibilidade e programação linear para corrigir os níveis de tensão e otimizar a alocação de reativos em sistemas de potência.

Publicação ENE-2/08, Departamento de Engenharia Elétrica, Universidade de Brasília, Brasília, DF, 49p.

\section{REFERÊNCIA BIBLIOGRÁFICA}

REZENDE, M. A. P. (2008). Utilização De Matriz Sensibilidade E Programação Linear Para Corrigir Os Níveis De Tensão E Otimizar A Alocação De Reativos Em Sistemas De Potência. Trabalho de Conclusão de Curso, Departamento de Engenharia Elétrica, Universidade de Brasília, Brasília, DF, 49p.

\section{CESSÃO DE DIREITOS}

AUTOR: Marcos Antonio Paes Rezende.

ORIENTADORA: Alessandra Macedo de Souza.

TÍTULO: Utilização de matriz sensibilidade e programação linear para corrigir os níveis de tensão e otimizar a alocação de reativos em sistemas de potência.

ANO: 2008

É concedida à Universidade de Brasília permissão para reproduzir cópias deste trabalho de conclusão de curso e para emprestar ou vender tais cópias somente para propósitos acadêmicos e científicos. O autor reserva outros direitos de publicação e nenhuma parte desse trabalho de conclusão de curso pode ser reproduzida sem autorização por escrito do autor. 


\section{DEDICATÓRIA}




\section{AGRADECIMENTOS}

A Deus, por tudo que aconteceu em minha vida.

Aos meu pais pelo apoio durante todo curso.

Ao meu irmão pela amizade.

A Cristiane pela ajuda com português.

A professora e orientadora Alessandra pela paciência e compreensão. 


\section{RESUMO}

\section{Alocação ótima de reativos em sistemas de potência utilizando matriz sensibilidade e otimização via programação linear no MATLAB}

AUTOR: Marcos Antonio Paes Rezende.

ORIENTADORA: Alessandra Macedo de Souza.

Brasília - Outubro de 2008

Este trabalho apresenta um método computacional para correção dos níveis de tensão de um sistema elétrico. As tensões são corrigidas com a alocação de reativos, usando a matriz sensibilidade do sistema para calcular a quantidade de reativos que deverão ser alocados e definir onde eles serão alocados.

O programa foi desenvolvido no MATLAB, utilizando a função linprog, que resolve problemas de otimização utilizando programação linear. Para a resolução do fluxo de carga foi adotado o método de Newton.

O programa foi testado em 3 sistemas conhecidos de 6, 14 e 30 barras e os resultados encontrados foram satisfatórios. É possível escolher os limites de tensão desejados e o método de otimização. Também podem ser escolhidas as tolerâncias desejadas para a resolução do fluxo de carga e para a alocação de reativos. 


\section{SUMÁRIO}

\section{CAPÍTULO 1}

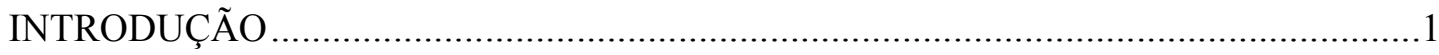

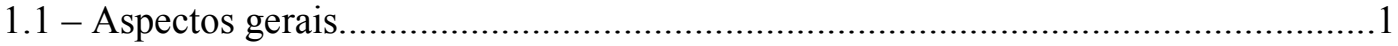

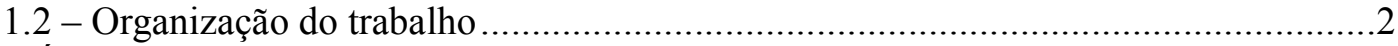

CAPÍTULO 2

FLUXO DE CARGA COM ALOCAÇÃO DE REATIVOS ................................................

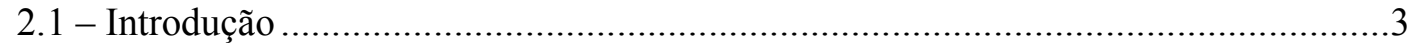

2.2 - Resolução do problema de fluxo de carga pelo método de Newton ..........................6

2.2.1 - O Método de Newton ..............................................................................

2.2.2 - O método de Newton aplicado ao problema de Fluxo de Carga.............................8

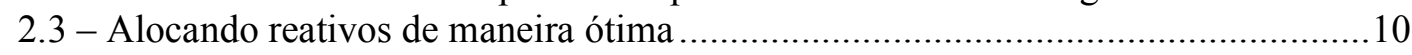

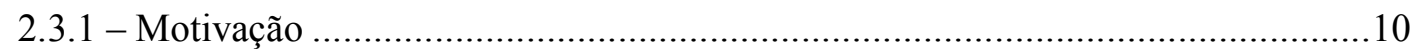

2.3.2 - Cálculo dos reativos a serem alocadas a partir da matriz sensibilidade ...............11

CAPÍTULO 3

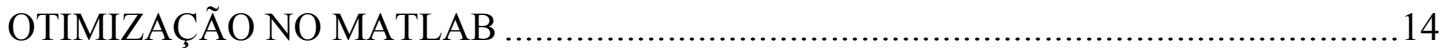

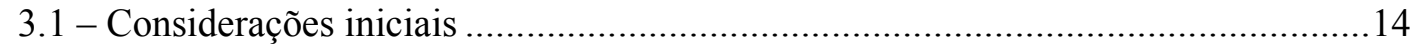

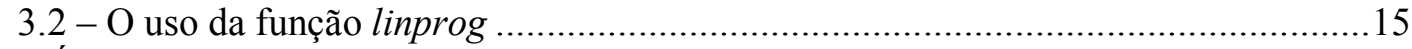

CAPÍTULO 4

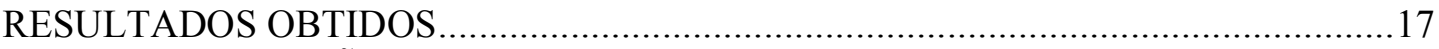

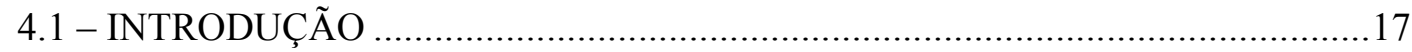

4.2 - Resultado do sistema WARD\&HALE de 6 barras ...............................................17

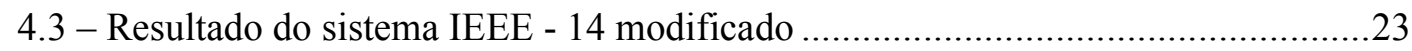

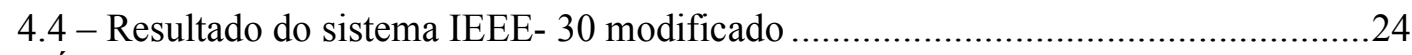

CAPÍTULO 5

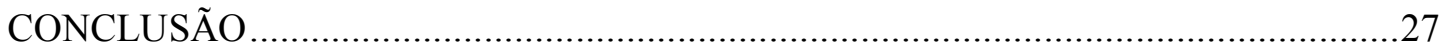

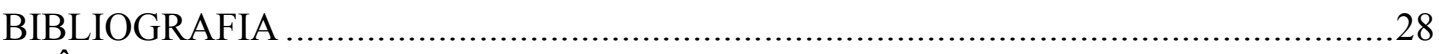

APÊNDICES

APÊNDICE A - DADOS DOS SISTEMAS UTILIZADOS ……………………...............

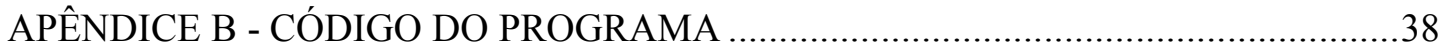




\section{LISTA DE FIGURAS}

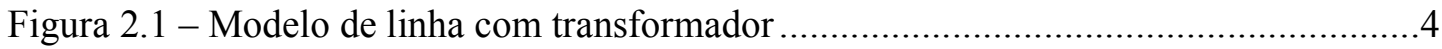

Figura 2.2 - Diagrama de fluxo do programa .......................................................... 13

Figura 4.1 - Evolução das tensões no sistema W\&H6 após sucessivas alocações de

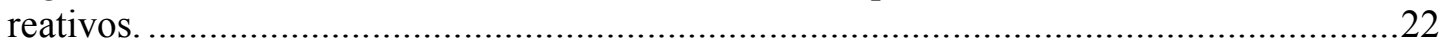

Figura 4.2 - Evolução das tensões no sistema IEEE-14 após sucessivas alocações de

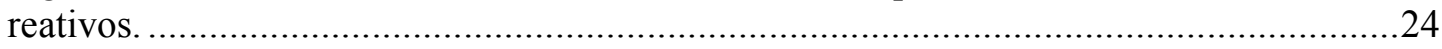

Figura 4.3 - Evolução das tensões no sistema IEEE-30 após sucessivas alocações de

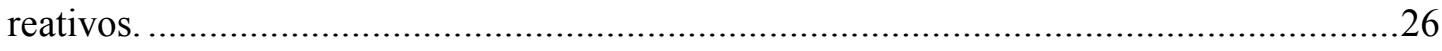

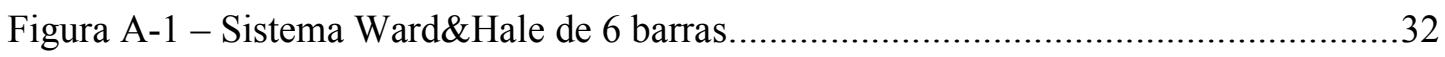

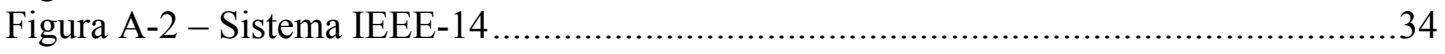

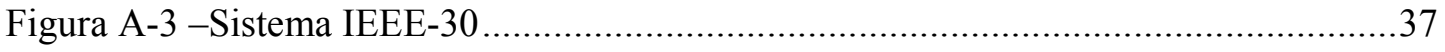




\section{LISTA DE TABELAS}

Tabela 4.1 - Tensões encontradas ao resolver o fluxo de carga do sistema W\&H6...........18 Tabela 4.2 - Tensões encontradas ao resolver o fluxo de carga após a primeira alocação de reativos do sistema $\mathrm{W} \& \mathrm{H} 6$

Tabela 4.3 - Tensões encontradas ao resolver o fluxo de carga após alocação de reativos do sistema W\&H6

Tabela 4.4 - Tensões encontradas ao resolver o fluxo de carga após alocação de reativos do sistema W\&H6

Tabela 4.5-Tensões encontradas ao resolver o fluxo de carga do sistema IEEE-14..........23

Tabela 4.6-Tensões encontradas após alocação de reativos no sistema IEEE-14 …..........23

Tabela 4.7-Tensões encontradas ao resolver o fluxo de carga do sistema IEEE-30..........25

Tabela 4.8-Tensões encontradas ao resolver o fluxo de carga após alocação de reativos do

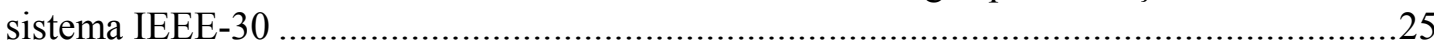

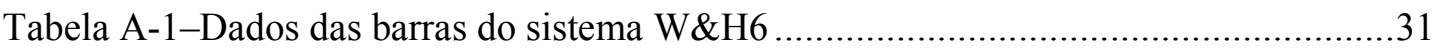

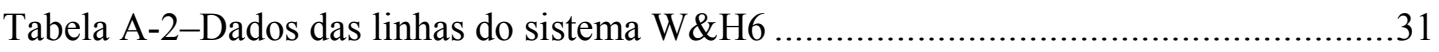

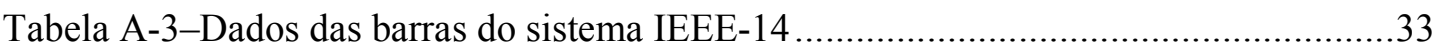

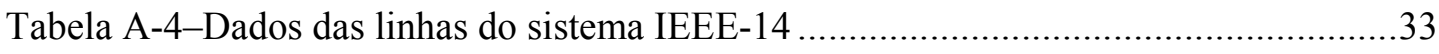

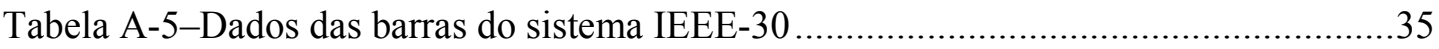

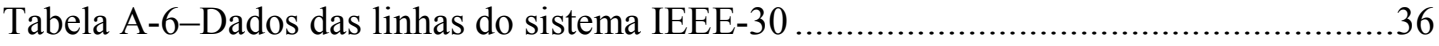




\section{CAPÍTULO 1 \\ INTRODUÇÃO}

\section{1 - Aspectos gerais}

Com o aumento dos sistemas de potência impulsionado pelo crescimento dos centros consumidores, torna-se necessário um cuidadoso planejamento para o fornecimento de energia de qualidade. Este planejamento envolve, entre outros assuntos, a alocação de potência reativa nos barramentos para a manutenção das tensões dentro de limites aceitáveis.

É desejável, para que os custos da implantação não sejam grandes, que seja alocado o mínimo possível de reativos. Métodos utilizados para a alocação de reativos são utilizados desde a década de 50. Eles utilizavam métodos analíticos a partir de simplificações do modelo do sistema de potência. Com a popularização dos computadores, métodos numéricos começaram a ser utilizados a partir da década de 70, (SOUSA, 2003).

Hoje, para o controle de tensão, existem métodos bem sofisticados que utilizam inteligência artificial através de Redes Neurais Artificiais (RNA) ou Lógica Fuzzy para a decisão, em tempo real, na atuação nos equipamentos de controle de tensão do sistema de potência (LIMA, 2007). Também existem técnicas de controle que incluem restrições dinâmicas aos geradores para um melhor planejamento dos locais e valores dos suportes de potência reativa, (OLIVEIRA, 2008).

Existe também outro método, que utiliza a alocação de reativos não só para obter tensões dentro de limites desejados, mas também para maximizar a capacidade de transferência de potência no sistema elétrico, (GOH, 2006).

Outro método com motivação mais econômica para a alocação de reativos em sistemas de potência com vários participantes não propõe uma solução de custo mínimo global, mas alocações de modo que cada participante cubra as suas perdas, (CHICCO, 2002).

No trabalho apresentado, para a otimização da alocação de reativos nos sistemas de potência, foi proposta uma metodologia que utiliza métodos numéricos, baseada na utilização de uma 
matriz que relaciona o impacto nas tensões do sistema com a alocação de potência reativa em uma barra. Essa matriz é chamada matriz sensibilidade. Este método foi baseado no descrito por SOUZA em 1997. A matriz sensibilidade é calculada no ponto de solução do problema de fluxo de carga. Tanto a matriz sensibilidade como o fluxo de carga foram calculados utilizando o programa MATLAB. Para a alocação ótima de reativos, foi usada a função linprog do MATLAB, que permite escolher dois métodos distintos de otimização. O programa de otimização utiliza as mesmas variáveis do programa de fluxo de carga e estão ambos embutidos no arquivo maloca.m mostrado no apêndice B.

O programa foi testado utilizando três sistemas: Ward\&Hale de 6 barras, IEEE-14 e IEEE-30. Os dados desses sistemas estão disponíveis no apêndice A.

\section{2 - Organização do trabalho}

O trabalho foi dividido em 5 capítulos. No primeiro, foi feita uma breve introdução ao problema de alocação de reativos e a apresentação dos objetivos do trabalho.

No segundo capítulo são apresentadas as formulações matemáticas necessárias para a resolução do fluxo de carga e para a alocação ótima de reativos

No capítulo seguinte é mostrado como a otimização será realizada no MATLAB.

Os resultados obtidos nos três sistemas testados utilizando o programa desenvolvido são apresentados no capítulo 4.

As conclusões do trabalho são apresentadas no capítulo final.

Nos apêndices são mostrados os dados dos sistemas utilizados, bem como todo código implementado. 


\section{1 - Introdução}

O problema de fluxo de carga fornece como solução o ponto de operação de um sistema de potência, isto é, a magnitude e a fase da tensão para todas as barras da rede elétrica. O fluxo de carga é obtido da aplicação da lei dos nós no sistema de potência. Para cada barra podem ser determinadas duas equações:

$$
\begin{gathered}
P_{k}=\sum_{m \in \Omega_{k}} P_{k m}\left(V_{k}, V_{m}, \theta_{k}, \theta_{m}\right) \\
Q_{k}+Q_{k}^{s h}\left(V_{k}\right)=\sum_{m \in \Omega_{k}} Q_{k m}\left(V_{k}, V_{m}, \theta_{k}, \theta_{m}\right)
\end{gathered}
$$

Em que:

- $\Omega_{\mathrm{k}}$ é o conjunto das barras vizinhas a barra k;

- $\mathrm{V}_{\mathrm{k}}$ é a magnitude do fasor de tensão na barra $\mathrm{k}$;

- $\theta_{\mathrm{k}}$ é o ângulo do fasor de tensão na barra k;

- $\mathrm{V}_{\mathrm{m}}$ é a magnitude do fasor de tensão na barra m;

- $\quad \theta_{\mathrm{m}}$ é o ângulo do fasor de tensão na barra m;

- $\mathrm{P}_{\mathrm{k}}$ é a geração líquida de potência ativa na barra $\mathrm{k}$ (geração menos carga);

- $\mathrm{Q}_{\mathrm{k}}$ é a injeção líquida de potência reativa na barra $\mathrm{k}$;

- $Q_{k}^{s h}$ é a injeção de potência reativa na barra k devido a um elemento shunt conectado a barra; 
- $\mathrm{P}_{\mathrm{km}}$ é o fluxo de potência ativa da barra k para a barra m;

- $\mathrm{Q}_{\mathrm{km}}$ é o fluxo de potência reativa da barra k para a barra $\mathrm{m}$.

Os fluxos $\mathrm{P}_{\mathrm{km}}$ e $\mathrm{Q}_{\mathrm{km}}$ podem ser obtidos a partir do modelo $\pi$ utilizado para as linhas de transmissão e para os transformadores, que são dados pelas expressões 2.3 e 2.4 (MONTICELLI, 1983). Para as linhas com um transformador o modelo adotado é o mostrado na Figura 2.1.

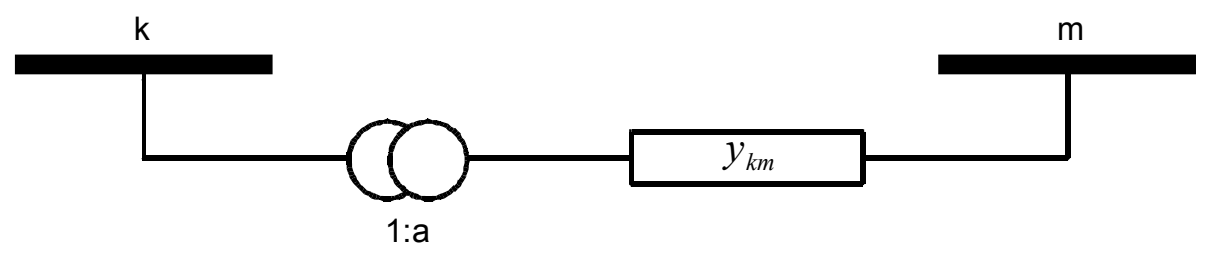

Figura 2.1 - Modelo de linha com transformador

$$
\begin{gathered}
P_{k m}=\left(a_{k m} V_{k}\right)^{2} g_{k m}-a_{k m} V_{k} V_{m} g_{k m} \cos \theta_{k m}-a_{k m} V_{k} V_{m} b_{k m} \operatorname{sen} \theta_{k m} \\
Q_{k m}=-\left(a_{k m} V_{k}\right)^{2}\left(b_{k m}+b_{k m}^{s h}\right)+a_{k m} V_{k} V_{m} b_{k m} \cos \theta_{k m}-a_{k m} V_{k} V_{m} g_{k m} \operatorname{sen} \theta_{k m}
\end{gathered}
$$

Em que:

- $\mathrm{a}_{\mathrm{km}}$ é a relação de transformação do transformador, conectado na barra $\mathrm{k}$, da linha de transmissão que vai da barra $\mathrm{k}$ para $\mathrm{m}$, se não há transformador na barra $\mathrm{k} \mathrm{a}_{\mathrm{km}}=1$;

- $g_{\mathrm{km}}$ é a condutância série da linha de transmissão que liga as barras k e m. É a parte real da admitância da linha $\left(\mathrm{y}_{\mathrm{km}}\right)$;

- $\quad b_{\mathrm{km}}$ é a susceptância série da linha de transmissão que liga as barras $\mathrm{k}$ e m. É a parte imaginária da admitância da linha $\left(\mathrm{y}_{\mathrm{km}}\right)$;

- $\theta_{\mathrm{km}}$ é a diferença angular entra as barras $\mathrm{k}$ e $\mathrm{m}\left(\theta_{\mathrm{k}}-\theta_{\mathrm{m}}\right)$;

Combinando as equações 2.3 e 2.4 com as equações 2.1 e 2.2 obtemos as duas equações básicas do fluxo de carga mostradas a seguir: 


$$
\begin{gathered}
P_{k}=V_{k} \sum_{m \in K} V_{m}\left(G_{k m} \cos \theta_{k m}+B_{k m} \operatorname{sen} \theta_{k m}\right) \\
Q_{k}=V_{k} \sum_{m \in K} V_{m}\left(G_{k m} \operatorname{sen} \theta_{k m}-B_{k m} \cos \theta_{k m}\right)
\end{gathered}
$$

Em que o conjunto $\mathrm{K}$ é formado pelo conjunto das barras adjacentes à barra $\mathrm{k}\left(\Omega_{k}\right)$ mais a própria barra $\mathrm{k}$. As matrizes representadas por $\mathrm{G}$ e B são formadas pelas componentes reais e imaginárias da matriz admitância e representam a condutância e a susceptância, respectivamente.

Para cada barra temos duas equações e quatro incógnitas $(P, Q, V$ e $\theta)$. Sendo assim, seria impossível encontrar uma solução única para o problema. Acontece que toda barra tem, pelo menos, duas dessas incógnitas determinadas pelas características delas no sistema elétrico. Serão considerados três tipos de barras:

- Barras PQ, também conhecidas como barras de carga, são as barras onde, geralmente, estão concentradas as unidades consumidoras. Nelas, o fasor de tensão não é fixado, mas a carga consumida é conhecida através de estudos prévios. Dados $\mathrm{P}$ e $\mathrm{Q}$, calculados $\mathrm{V}$ e $\theta$.

- Barras PV, também chamadas de barras geradoras ou de tensão controlada, são as barras onde estão conectados os geradores. A potência gerada por um gerador e sua tensão é determinada pelo operador do sistema. Dados P e V, calculados Q e $\theta$.

- Barras V $\theta$, também conhecidas como barras de folga ou slack, são as barras onde é especificado um ângulo de referência e a tensão é fixa. A potência gerada por ela não é fixada, pois ela é a barra que irá suprir a potência consumida por perdas de transmissão. Dados V e $\theta$, calculados P e Q.

Utilizando estes três tipos de barra, é possível eliminar algumas incógnitas das equações 2.5 e 2.6. O sistema elétrico de $n$ barras fica, então, com $2 n$ equações e $2 n$ variáveis, existindo, assim, uma solução única para o sistema de equações. 


\section{2 - Resolução do problema de fluxo de carga pelo método de Newton}

Uma vez obtido o sistema com 2 n equações e $2 n$ incógnitas, o método de resolução utilizado se baseia em dividir estas equações em dois subsistemas: um onde serão obtidos os fasores de tensões das barras e outro onde será obtida a potência complexa consumida ou fornecida em cada barra. O primeiro subsistema será resolvido utilizando o método de Newton. O segundo, utilizando as expressões de injeção de potência das equações 2.5 e 2.6. O primeiro subsistema exige mais esforço computacional, pois é um método iterativo que requer uma inversão matricial, procedimento muito dispendioso em termos computacionais, a cada iteração.

\subsection{1 - O Método de Newton}

Para a resolução do sistema foi usado o método de Newton para sistemas de equações nãolineares. Este método pode ser considerado uma ampliação do método Newton-Raphson, que resolve equações a partir de uma aproximação linear e iterativa, (RUGGIERO, 2004).

O método de Newton-Raphson é utilizado para encontrar zeros de funções da seguinte maneira:

Seja a equação $\mathrm{f}(\mathrm{x})=0$.

1. Dados iniciais necessários: aproximação inicial $x_{0}$ e critério de parada $\varepsilon, \mathrm{k}=0$;

2. Verificar se $\left|f\left(x_{k}\right)\right| \leq \varepsilon$, se sim, o método convergiu para $x_{k}$ com a precisão desejada, se não, ir para o passo 3

3. Atualizar o valor de $\mathrm{x}$ a partir da forma de iteração:

$$
x_{k+1}=x_{k}-\frac{f\left(x_{k}\right)}{f^{\prime}\left(x_{k}\right)}
$$

4. $\mathrm{k}=\mathrm{k}+1$ 


\section{Voltar ao passo 2.}

Utilizando este procedimento, haverá convergência em um intervalo em torno do zero da equação se $f(x), f^{\prime}(x)$ e $f^{\prime \prime}(x)$ forem contínuas. O procedimento de resolução do sistema de equações não-lineares é mostrado a seguir:

Seja um sistema de equações dado por:

$$
F(\bar{x})=\left(\begin{array}{c}
f_{1}\left(x_{1}, x_{2}, \cdots, x_{n}\right) \\
f_{2}\left(x_{1}, x_{2}, \cdots, x_{n}\right) \\
\vdots \\
f_{n}\left(x_{1}, x_{2}, \cdots, x_{n}\right)
\end{array}\right)
$$

Deseja-se encontrar:

$$
F(\bar{x})=0
$$

O procedimento de resolução é similar. Uma diferença é que, ao invés da utilização de uma derivada simples, é utilizado o gradiente das equações. A matriz formada pelos gradientes das equações é denominada matriz Jacobiana e é mostrada a seguir:

$$
J(\bar{x})=\left[\begin{array}{cccc}
\frac{\partial f_{1}(x)}{\partial x_{1}} & \frac{\partial f_{1}(x)}{\partial x_{2}} & \cdots & \frac{\partial f_{1}(x)}{\partial x_{n}} \\
\frac{\partial f_{2}(x)}{\partial x_{1}} & \frac{\partial f_{2}(x)}{\partial x_{2}} & \cdots & \frac{\partial f_{2}(x)}{\partial x_{n}} \\
\vdots & \vdots & \ddots & \vdots \\
\frac{\partial f_{n}(x)}{\partial x_{1}} & \frac{\partial f_{n}(x)}{\partial x_{2}} & \cdots & \frac{\partial f_{n}(x)}{\partial x_{n}}
\end{array}\right]
$$

O método de Newton para encontrar $\bar{x}$ tal que $\mathrm{F}(\bar{x})=0$ consiste nos seguintes passos:

1. Dados iniciais necessários: aproximação inicial $\overline{x_{0}}$ e critério de parada $\varepsilon, \mathrm{k}=0$;

2. Calcule $F\left(\overline{x_{k}}\right)$ 
3. Verificar se $\left|F\left(\overline{x_{k}}\right)\right| \leq \varepsilon$, se sim o método convergiu para $\bar{x}=\overline{x_{k}}$ com a precisão desejada, se não ir para o passo 4;

4. Calcular a matriz Jacobiana $\left(J\left(\overline{x_{k}}\right)\right)$;

5. Obter o vetor de correções $\Delta x=-[J(x)]^{-1} F(x)$, solução do sistema linear: $J\left(\overline{x_{k}}\right) \Delta x=-F\left(\overline{x_{k}}\right)$;

6. Calcular o novo ponto $x_{k+1}=x_{k}+\Delta x$;

7. $\mathrm{k}=\mathrm{k}+1$;

8. Voltar para o passo 2

\subsection{2 - O método de Newton aplicado ao problema de Fluxo de Carga}

O subsistema 1, onde será encontrado $\mathrm{V}$ e $\theta$ é composto pelas equações:

$$
\begin{gathered}
P_{k}^{e s p}-V_{k} \sum_{m \in K} V_{m}\left(G_{k m} \cos \theta_{k m}+B_{k m} \operatorname{sen} \theta_{k m}\right)=0 \\
Q_{k}^{e s p}+V_{k} \sum_{m \in K} V_{m}\left(G_{k m} \operatorname{sen} \theta_{k m}-B_{k m} \cos \theta_{k m}\right)=0
\end{gathered}
$$

Em que:

- $\quad P_{k}^{e s p}$ é a potência ativa gerada ou consumida na barra k. Esta potência é conhecida nas barras PV e PQ;

- $Q_{k}^{e s p}$ é a potência reativa consumida na barra k. Esta potência é conhecida PQ;

Sendo que para as barras PQ são resolvidas as equações 2.11 e 2.12 e para as barras PV somente a equação 2.11, resultando num sistema com $2 \mathrm{NPQ}+\mathrm{NPV}$ equações. O sistema de equações será representado por: 


$$
F(\bar{x})=\left[\begin{array}{c}
P_{i}^{e s p}-V i \sum_{m \in K} V_{m}\left(G_{i m} \cos \theta_{i m}+B_{i m} \operatorname{sen} \theta_{i m}\right) \\
Q_{j}^{e s p}+V_{j} \sum_{m \in K} V_{m}\left(G_{j m} \operatorname{sen} \theta_{j m}-B_{j m} \cos \theta_{j m}\right)
\end{array}\right]
$$

Em que $\bar{x}=\left[\begin{array}{c}\theta_{i} \\ V_{j}\end{array}\right]$, e i é o conjunto formado pelas barras PV e PQ e j o conjunto das barras PQ.

Para a resolução do sistema de equações, aplica-se o método de Newton, como mostrado na seção anterior. As aproximações iniciais são feitas iguais a 1 p.u.para as tensões e 0 para os ângulos. Esta aproximação é razoável porque os valores no sistema de potência não diferem muito desses. Nesse caso específico, o Jacobiano $J(\bar{x})$ é determinado por:

$$
J(\bar{x})=-\left[\begin{array}{ll}
\frac{\partial \bar{P}_{i}}{\partial \bar{\theta}_{i}} & \frac{\partial \bar{P}_{i}}{\partial \bar{V}_{j}} \\
\frac{\partial \overline{Q_{j}}}{\partial \bar{\theta}_{i}} & \frac{\partial \overline{Q_{j}}}{\partial \overline{V_{j}}}
\end{array}\right]
$$

Para leitura mais fácil, as submatrizes da matriz Jacobiana são representadas por:

$$
J(\bar{x})=\left[\begin{array}{ll}
H & N \\
M & L
\end{array}\right]
$$

Existem expressões gerais para as matrizes $\mathrm{H}, \mathrm{M}, \mathrm{N}$ e L, sendo que não é necessário aplicar a derivada em toda iteração. Nesta situação deve-se utilizar as equações de 2.16 a 2.23 a seguir:

Submatriz H:

$$
\begin{gathered}
H_{k m}=V_{k} V_{m}\left(G_{k m} \operatorname{sen} \theta_{k m}-B_{k m} \cos \theta_{k m}\right) \\
H_{k k}=-Q_{k}-V_{k}^{2} B_{k k}
\end{gathered}
$$

Submatriz M

$$
\begin{gathered}
M_{k m}=-V_{k} V_{m}\left(G_{k m} \cos \theta_{k m}+B_{k m} \operatorname{sen} \theta_{k m}\right) \\
M_{k k}=P_{k}-V_{k}^{2} G_{k k}
\end{gathered}
$$


Submatriz N

$$
\begin{gathered}
N_{k m}=V_{k}\left(G_{k m} \cos \theta_{k m}+B_{k m} \operatorname{sen} \theta_{k m}\right) \\
N_{k k}=V_{k}^{-1}\left(P_{k}+V_{k}^{2} G_{k k}\right)
\end{gathered}
$$

Submatriz L

$$
\begin{gathered}
L_{k m}=V_{k}\left(G_{k m} \operatorname{sen} \theta_{k m}-B_{k m} \cos \theta_{k m}\right) \\
L_{k k}=V_{k}^{-1}\left(Q_{k}-V_{k}^{2} B_{k k}\right)
\end{gathered}
$$

Após aplicar o método de Newton, são obtidos todos os fasores de tensão do sistema. Com V e $\theta$ determinados, as injeções de potência em cada barra podem ser calculados pelas equações 2.5 e 2.6. Uma vez determinadas todas as variáveis, o problema do fluxo de carga está resolvido.

\section{3 - Alocando reativos de maneira ótima}

Após a resolução do problema do fluxo de carga, algumas tensões podem estar fora de limites para adequados para prejudiquem o bom funcionamento do sistema. Este trabalho propõe uma metodologia para a correção das tensões alocando reativos nas barras. Os reativos são alocados de maneira a se otimizar quantidade de reativos para a correção das tensões dentro dos limites desejados.

\subsection{1 - Motivação}

Caso uma barra se encontre com tensão muito elevada, equipamentos da subestação e/ou do consumidor final podem ser danificados. Por outro lado, se a tensão estiver baixa alguns componentes de eletrônica de potência e motores podem não funcionar corretamente. Por 
estes motivos, é necessário que as tensões em todas as barras do sistema de potência estejam dentro de limites aceitáveis.

Uma solução para a correção dos níveis de tensão é alocar fontes de reativos nas barras. Como as magnitudes das tensões estão ligadas fortemente à transferência de potência reativa entre as barras, a alocação de reativos em uma barra altera o fluxo de potência reativa necessário e, portanto, as tensões nas barras. Estes reativos podem ser alocados com capacitores e reatores em paralelo com a barra, compensadores síncronos e estáticos ou atuando nos próprios geradores, (GOH, 2006), (CHICCO, 2002).

\subsection{2 - Cálculo dos reativos a serem alocadas a partir da matriz sensibilidade}

Usualmente, para corrigir as tensões fora dos limites, os reativos são alocados nas barras onde as tensões estão abaixo do limite desejado. Esta metodologia corrige os níveis de tensão, mas não garante que será alocado o mínimo de reativos para isto. O método proposto utiliza uma matriz sensibilidade que relaciona, para o ponto resultante do fluxo de carga, quanto uma variação na injeção de reativos em uma barra gera de variação de tensão nas outras barras. Por simplicidade, só serão consideradas injeções em barras PQ.

A matriz sensibilidade utilizada $\left(\frac{\partial V}{\partial Q}\right)$ pode ser obtida calculando a inversa da submatriz L do jacobiano $\left(\frac{\partial Q}{\partial V}\right)$. A submatriz L será calculada utilizando as equações 2.22 e 2.23 e será invertida para a obtenção da matriz sensibilidade desejada. Com esta matriz, é possível saber onde a alocação de reativos é mais sensível, resultando em alocações nas barras que mais afetam as tensões a serem corrigidas.

Assim resolve-se o seguinte problema de otimização, também chamado de problema de programação linear (PL): 


$$
\begin{array}{ll}
\text { Minimizar } & \sum_{j} \Delta Q \\
\text { Sujeito a } & S^{*} \Delta Q \geq V_{j}^{\min }-V_{j} \\
& S^{*} \Delta Q \leq V_{j}^{\max }-V_{j} \\
& \Delta Q \geq 0
\end{array}
$$

Em que:

- $\mathrm{j}$ representa as barras onde podem ser alocados reativos;

- S é a matriz sensibilidade;

- $\Delta Q$ é um vetor com todas alocações feitas nas barras j.

Resolvendo este problema, obtemos as injeções de potência reativa $\Delta Q_{j}$ que minimiza a potência a ser alocada para manter o nível de tensão entre $V^{\min }$ e $V^{\max }$. Com as devidas injeções de potência reativa, é necessário acrescentar essas potências no problema de fluxo de carga e novamente resolvê-lo para obter o estado resultante do sistema após as alocações de reativos.

Um problema que acontece é devido à simplificação feita anteriormente de calcular $\mathrm{S}$ somente para o ponto desejado. Como S não considera as não-linearidades do sistema e foi calculada para um ponto específico, caso seja necessário a injeção de muitos reativos, o comportamento do sistema poderá mudar. Entretanto, no problema de otimização, a matriz sensibilidade é considerada a mesma. Portanto, é possível que, após a resolução do fluxo de carga, algumas tensões estejam fora dos limites, mesmo sendo uma restrição do problema de otimização que as tensões devem estar dento dos limites desejados.

Este problema foi solucionado recalculando a matriz sensibilidade para o novo estado do sistema resultante da resolução do fluxo de carga com as alocações obtidas na resolução do PL. O novo estado do sistema, embora ainda fora dos limites desejados, encontra-se mais próximo do estado onde as tensões estão dentro dos limites, pois já foi resolvido um PL visando corrigir as tensões do sistema. A cada iteração, as tensões ficam mais próximas dos limites desejados e há a convergência para um estado onde as tensões estejam dentro dos 
limites. Como a convergência é lenta, é possível parar as iterações caso se esteja próximo o suficiente das tensões desejadas.

A metodologia proposta é representada pelo fluxograma, representado na Figura 2.2.

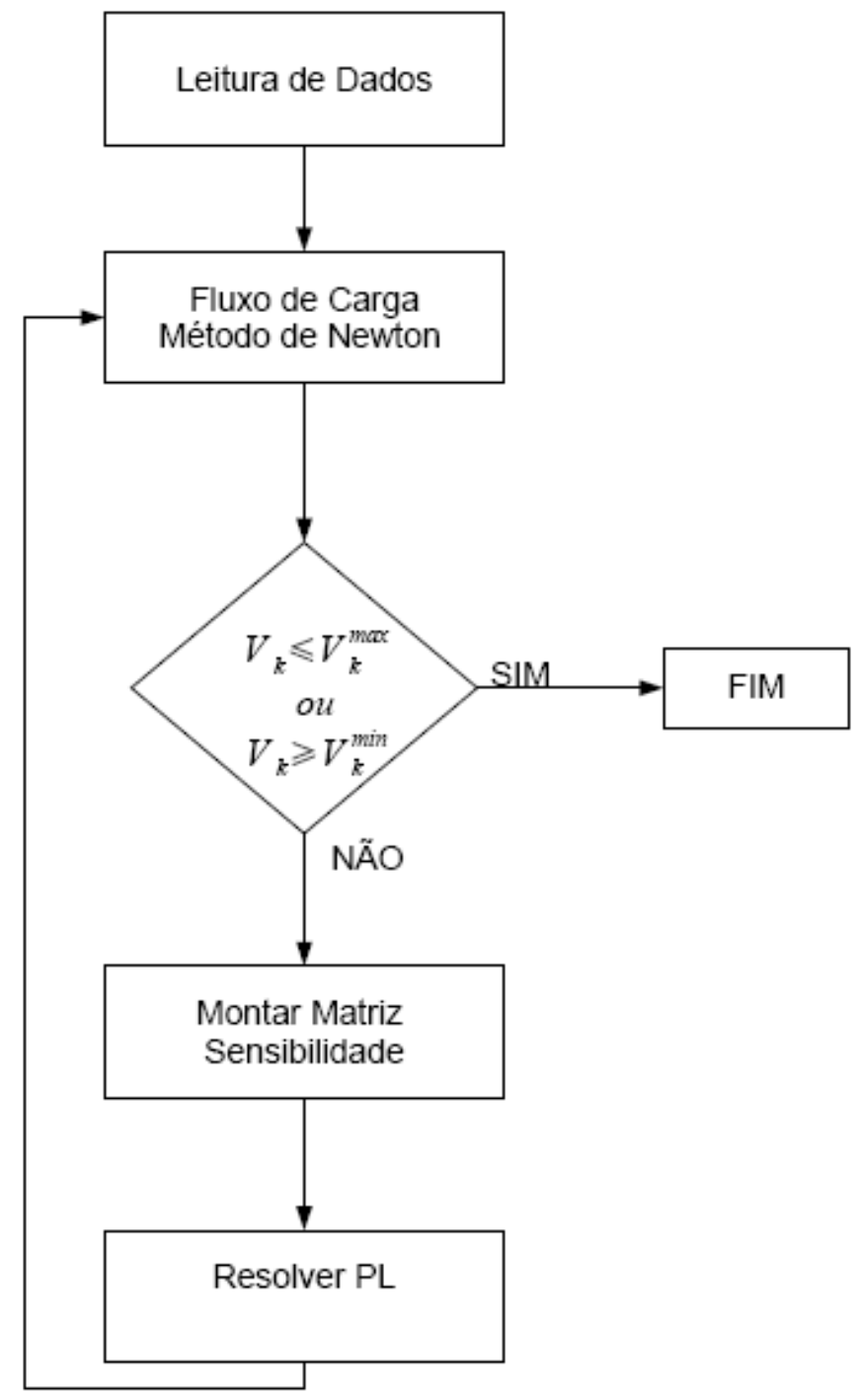

Figura 2.2 - Diagrama de fluxo do programa 


\section{CAPÍTULO 3 \\ OTIMIZAÇÃO NO MATLAB}

\section{1 - Considerações iniciais}

A toolbox de otimização presente no MATLAB apresenta diversas funções que podem ser aplicadas em diversos problemas de otimização. Para o problema da otimização dos reativos a serem alocados, que tem uma função linear a ser minimizada (a soma dos reativos alocados), a função mais simples para ser utilizada é a linprog. Existem outras funções mais gerais, como por exemplo, fmincon, fminunc, quadprog entre outras, que geram os mesmos resultados, mas como estas exigem mais dados de entrada, será utilizada, por simplicidade, a linprog. A linprog resolve problemas do tipo:

$$
\begin{array}{ll}
\text { Minimizar } & f(x) \\
\text { Sujeito } a & A^{*} x \geq b \\
& \text { Aeq } * x=b e q \\
& l b \leq x \leq u b
\end{array}
$$

A função linprog resolve os problemas de programação linear utilizando dois algoritmos distintos. O padrão é o denominado Large-Scale, que utiliza o método de ponto interior Primal-Dual. Outro método que pode ser utilizado é o método simplex, um dos métodos mais conhecidos para otimização. O método simplex encontra o mínimo da função percorrendo o poliedro formado pelas restrições que são feitas à função a ser minimizada. O Método de Ponto Interior pode percorrer um caminho que contenha pontos interiores ao poliedro, incluído o próprio poliedro, sendo, assim, mais abrangente que o simplex. Mais informações sobre estes métodos podem ser encontradas em DANTZIG (1955) e MEHROTRA (1992). A escolha do método que será utilizado é feita com a função optimset

No programa desenvolvido, pode-se escolher qual método será utilizado. O método simplex será usado como padrão, pois resulta numa otimização mais rápida, embora não tão abrangente quanto à do método de ponto interior. 


\section{2 - O uso da função linprog}

A função linprog deve ser chamada utilizando, pelo menos, três parâmetros:

- Os coeficientes “f” da função linear a ser utilizada;

- A matriz "A" com os coeficientes do sistema de desigualdades, esse sistema é da forma $A^{*} \mathrm{x} \leq \mathrm{b}$;

- O vetor coluna " $b$ " dos termos independentes do sistema de desigualdades.

A chamada da função é feita utilizando o seguinte comando no MATLAB:

$>>\mathrm{xmin}=\operatorname{linprog}(\mathrm{f}, \mathrm{A}, \mathrm{b})$

Dessa forma os valores de $\mathrm{x},\{\mathrm{x} 1, \mathrm{x} 2, \mathrm{x} 3, \ldots\}$ que minimizam a função linear $\mathrm{f}(\mathrm{x})$, de $\mathrm{n}$ variáveis, determinada pelos coeficientes “f” é armazenado na variável xmin, sendo que a xmin é um vetor coluna com os valores que, aplicados à função f, a minimizam.

Adicionalmente, é possível incluir restrições de igualdade, limites superiores e inferiores para os valores de $\mathrm{x}$, e incluir um ponto inicial (desprezado, se o método utilizado for o simplex), além de diversas opções sobre a execução da rotina de otimização (método de otimização, tolerância, e métodos de cálculo de diversas matrizes utilizadas na otimização). Estas novas restrições são passadas à função utilizando os seguintes parâmetros:

- A matriz "Aeq" com os coeficientes do sistema de igualdades, esse sistema é da forma Aeq * $\mathrm{x} \leq$ beq;

- O vetor coluna "beq" dos termos independentes do sistema de igualdades;

- O vetor coluna "lb", com os limites inferiores que os valores de x podem assumir;

- O vetor coluna "ub", com os limites superiores que os valores de x podem assumir;

- O vetor " $\mathrm{x} 0$ " com o ponto inicial para o método de ponto interior, este vetor é desprezado no método simplex e, se deixado em branco na utilização do método de ponto interior, o sistema calcula um ponto inicial. 
- As opções são passadas com a função optimset. O uso do optimset é feito da seguinte maneira:

>>options=optimset("variável", "valor")

Existem 44 variáveis que podem ter seu valor ajustados pelo optimset. No programa só serão utilizadas as simplex e Large-Scale, utilizadas para escolha do método de otimização. Esta escolha é feita com os seguintes comandos:

> >options = optimset('LargeScale', 'off', 'Simplex', 'on'), para a utilização do método simplex.

>>options = optimset('LargeScale', 'on', 'Simplex', 'off'), para a utilização do método Large-Scale.

A chamada completa para a função fica então da seguinte maneira:

$>>$ xmin $=\operatorname{linprog}(\mathrm{f}, \mathrm{A}, \mathrm{b}, \mathrm{Aeq}, \mathrm{beq}, \mathrm{lb}, \mathrm{ub}, \mathrm{x} 0, \mathrm{options})$

É importante notar que a ordem em que os argumentos são passados à função não pode mudar. Se não há uma restrição que é passada como argumento da função antes de outra que existe, aquela deve ser indicada com um vetor vazio.

No problema proposto (eq. 2.24), só existem restrições de desigualdades e, por isso, o uso da função linprog será feito apenas com os três argumentos mínimos. Caso fossem propostas mais restrições, elas deveriam ser acrescentadas utilizando a mesma lógica mostrada anteriormente. 


\section{CAPÍTULO 4 RESULTADOS OBTIDOS}

\section{1 - INTRODUÇÃO}

Para testar o que foi proposto, foi elaborado um programa em MATLAB que implementa o que já foi discutido anteriormente neste trabalho. Este programa foi testado em variações dos sistemas WARD\&HALE de 6 barras, IEEE 14 e 30 barras. Como todos estes sistemas apresentam barras de tensão controlada com tensões acima do limite de $5 \%$ da tensão nominal, foi utilizado, por coerência, o limite de tensão de $\pm 5 \%$ da tensão nominal.

Os sistemas, nas situações de carga descritas, apresentam as tensões dentro ou bem perto do limite, sendo necessário nenhuma ou pouca potência reativa alocada para corrigir as tensões. Para mostrar melhor o comportamento do programa, as cargas consideradas foram maiores para gerar mais tensões fora do limite de 5\%. Assim, podemos ver melhor a decisão, tomada pelo programa, de onde alocar os reativos.

O programa foi rodado utilizando o método simplex e o Large-Scale, mas, em ambos os casos, os resultados obtidos foram os mesmos.

\section{2 - Resultado do sistema WARD\&HALE de 6 barras}

O sistema Ward\&Hale de seis barras (W\&H6) é o mostrado no apêndice A - 1. Esse sistema foi modificado aumentando as cargas em 50\%. Após a solução do fluxo de carga foram encontradas as tensões mostradas na Tabela 4.1: 
Tabela 4.1 - Tensões encontradas ao resolver o fluxo de carga do sistema W\&H6

\begin{tabular}{|c|c|c|}
\hline Barra & Tipo & Tensão (p.u.) \\
\hline 1 & V $\theta$ & 1,0500 \\
\hline 2 & PV & 1,1000 \\
\hline 3 & PQ & 0,7184 \\
\hline 4 & PQ & 0,8019 \\
\hline 5 & PQ & 0,7481 \\
\hline 6 & PQ & 0,7590 \\
\hline
\end{tabular}

Com os limites propostos, as tensões devem estar entre 0,95 p.u. e 1,05 p.u. $( \pm 5 \%)$. Em todas as barras PQ as tensões estão fora do intervalo desejado. A rotina de otimização será então aplicada ao sistema. A matriz sensibilidade deste sistema tem a forma mostrada na eq. 4.1.

$$
S=\left[\begin{array}{llll}
\frac{\partial V_{3}}{\partial Q_{3}} & \frac{\partial V_{3}}{\partial Q_{4}} & \frac{\partial V_{3}}{\partial Q_{5}} & \frac{\partial V_{3}}{\partial Q_{6}} \\
\frac{\partial V_{4}}{\partial Q_{3}} & \frac{\partial V_{4}}{\partial Q_{4}} & \frac{\partial V_{4}}{\partial Q_{5}} & \frac{\partial V_{4}}{\partial Q_{6}} \\
\frac{\partial V_{5}}{\partial Q_{3}} & \frac{\partial V_{5}}{\partial Q_{4}} & \frac{\partial V_{5}}{\partial Q_{5}} & \frac{\partial V_{5}}{\partial Q_{6}} \\
\frac{\partial V_{6}}{\partial Q_{3}} & \frac{\partial V_{6}}{\partial Q_{4}} & \frac{\partial V_{6}}{\partial Q_{5}} & \frac{\partial V_{6}}{\partial Q_{6}}
\end{array}\right]
$$

O programa calcula a matriz sensibilidade para o ponto encontrado após a resolução do fluxo de carga mostrada na Tabela 4.1. A matriz sensibilidade encontrada é:

$$
S=\left[\begin{array}{llll}
0,4046 & 0,2625 & 0,1119 & 0,1405 \\
0,2931 & 0,3006 & 0,1281 & 0,1609 \\
0,1097 & 0,1126 & 0,5323 & 0,2807 \\
0,1398 & 0,1434 & 0,2848 & 0,3577
\end{array}\right]
$$

O problema de otimização para esse caso, obtido a partir da equação 2.24 , é mostrado na equação 4.3. Os valores nas colunas a direita das inequações representam as variações de tensão desejadas para as tensões ficarem acima da tensão mínima e abaixo da tensão máxima estabelecida: 
Minimizar $\quad \Delta Q_{3}+\Delta Q_{4}+\Delta Q_{5}+\Delta Q_{6}$

$\begin{aligned} \text { Sujeito } a & {\left[\begin{array}{llll}0,4046 & 0,2625 & 0,1119 & 0,1405 \\ 0,2931 & 0,3006 & 0,1281 & 0,1609 \\ 0,1097 & 0,1126 & 0,5323 & 0,2807 \\ 0,1398 & 0,1434 & 0,2848 & 0,3577\end{array}\right] *\left[\begin{array}{c}\Delta Q_{3} \\ \Delta Q_{4} \\ \Delta Q_{5} \\ \Delta Q_{6}\end{array}\right] \geq\left[\begin{array}{c}0,2316 \\ 0,1481 \\ 0,2019 \\ 0,1910\end{array}\right] } \\ & {\left[\begin{array}{llll}0,4046 & 0,2625 & 0,1119 & 0,1405 \\ 0,2931 & 0,3006 & 0,1281 & 0,1609 \\ 0,1097 & 0,1126 & 0,5323 & 0,2807 \\ 0,1398 & 0,1434 & 0,2848 & 0,3577\end{array}\right] *\left[\begin{array}{l}\Delta Q_{3} \\ \Delta Q_{4} \\ \Delta Q_{5} \\ \Delta Q_{6}\end{array}\right] \leq\left[\begin{array}{l}0,3316 \\ 0,2481 \\ 0,3019 \\ 0,2910\end{array}\right] }\end{aligned}$ $\left[\begin{array}{llll}1 & 0 & 0 & 0 \\ 0 & 1 & 0 & 0 \\ 0 & 0 & 1 & 0 \\ 0 & 0 & 0 & 1\end{array}\right] *\left[\begin{array}{c}\Delta Q_{3} \\ \Delta Q_{4} \\ \Delta Q_{5} \\ \Delta Q_{6}\end{array}\right] \geq\left[\begin{array}{l}0 \\ 0 \\ 0 \\ 0\end{array}\right]$

Para a resolução do problema no MATLAB foi usada a função linprog como mostrado no capítulo 3. Como as inequações para a função linprog são do tipo $A^{*} \mathrm{x} \leq \mathrm{b}$, os termos onde aparecem $A^{*} \mathrm{x} \geq \mathrm{b}$ serão multiplicados por -1 .

A matriz A que contem os coeficientes do sistema de desigualdades é então criada utilizando o seguinte comando no MATLAB:

$>\mathrm{A}=[-1 * \mathrm{~S} ; \mathrm{S} ;-1 *$ eye $(\mathrm{NPQ})]$

Onde S é a matriz sensibilidade e a função eye retorna uma matiz identidade com dimensões NPQxNPQ.

O vetor-coluna com os termos independentes é criado utilizando o seguinte comando:

$>>b=[\operatorname{vm}(\mathrm{iq})-\mathrm{Vmin} ; \operatorname{Vmax}-\mathrm{vm}(\mathrm{iq}) ; \operatorname{zeros}(\operatorname{size}(\mathrm{iq}))]$

A função zeros retorna uma matriz somente com zeros com a dimensão desejada. A função size(iq) retorna as dimensões da matriz iq, que é um vetor-coluna com os números das barras PQ. 
A função a ser minimizada, a soma dos reativos injetados, é dada por $\Delta Q_{3}+\Delta Q_{4}+\Delta Q_{5}+\Delta Q_{6}$, logo os coeficientes são todos unitários. Um vetor com estes coeficientes é criado utilizando o seguinte comando:

$>\mathrm{f}=$ ones(size $(\mathrm{iq}))$;

A função ones retorna uma matriz somente com todos valores sendo unitários, com a dimensão passada como argumento. Para o MATLAB os coeficientes da função a ser minimizada devem ser passados como um vetor-linha.

A função linprog pode ser chamada utilizando o seguinte comando:

$>>\mathrm{xmin}=\operatorname{linprog}(\mathrm{f}, \mathrm{A}, \mathrm{b})$;

Os valores das injeções que resolvem o problema de otimização são guardados na variável xmin. Estes valores são adicionados as potências reativas líquidas injetadas em cada barra com o comando:

$>>\mathrm{QN}(\mathrm{iq})=\mathrm{QN}(\mathrm{iq})+\mathrm{xmin}$

Após isso é novamente calculado o fluxo de carga, com as novas injeções de potência, para a obtenção do estado do sistema após a alocação de reativos. O estado do sistema resultante após a alocação é mostrado na Tabela 4.2, a coluna com o $\Delta \mathrm{Q}$ representa as alocações encontradas após a otimização.

Tabela 4.2 - Tensões encontradas ao resolver o fluxo de carga após a primeira alocação de reativos do sistema W\&H6

\begin{tabular}{|c|c|c|c|}
\hline Barra & Tipo & Tensão (p.u.) & $\Delta$ Q (p.u.) \\
\hline 1 & V $\theta$ & 1,0500 & - \\
\hline 2 & PV & 1,1000 & - \\
\hline 3 & PQ & 0,9334 & 0,4479 \\
\hline 4 & PQ & 0,9930 & 0,0000 \\
\hline 5 & PQ & 0,9327 & 0,1685 \\
\hline 6 & PQ & 0,9606 & 0,2247 \\
\hline
\end{tabular}

Neste caso, mesmo após a alocação, as tensões nas barras 3 e 5 ainda estão fora do limite de 5\% desejado, mas bem mais próximo do que no caso inicial. Nessa situação, a matriz sensibilidade é calculada para o estado resultante. A matriz sensibilidade neste ponto é: 


$$
S=\left[\begin{array}{llll}
0,2630 & 0,1789 & 0,0632 & 0,0845 \\
0,1903 & 0,2179 & 0,0770 & 0,1029 \\
0,0610 & 0,0698 & 0,3628 & 0,1794 \\
0,0839 & 0,0960 & 0,1848 & 0,2468
\end{array}\right]
$$

O processo de otimização é novamente aplicado, utilizando a matriz sensibilidade mostrada na equação 4.4. As tensões encontradas após uma segunda alocação de reativos são mostradas na Tabela 4.3

Tabela 4.3 - Tensões encontradas ao resolver o fluxo de carga após alocação de reativos do sistema W\&H6

\begin{tabular}{|c|c|c|c|}
\hline Barra & Tipo & Tensão (p.u.) & $\Delta$ Q (p.u.) \\
\hline 1 & V $\theta$ & 1,0500 & - \\
\hline 2 & PV & 1,1000 & - \\
\hline 3 & PQ & 0,9502 & 0,5017 \\
\hline 4 & PQ & 1,0068 & 0,0000 \\
\hline 5 & PQ & 0,9496 & 0,2070 \\
\hline 6 & PQ & 0,9732 & 0,2247 \\
\hline
\end{tabular}

Somente tensão na barra 5 ainda está fora do limite de $5 \%$, sendo necessária mais uma alocação. Nesta última alocação foram alocados menos reativos do que na primeira, pois os níveis já estavam mais próximos do desejado. Para este novo estado do sistema a matriz sensibilidade é dada por:

$$
S=\left[\begin{array}{llll}
0,2554 & 0,1744 & 0,0605 & 0,0820 \\
0,1848 & 0,2134 & 0,0741 & 0,1004 \\
0,0584 & 0,0675 & 0,3508 & 0,1744 \\
0,0812 & 0,0938 & 0,1787 & 0,2422
\end{array}\right]
$$

O processo de otimização é novamente aplicado, utilizando a matriz sensibilidade mostrada na equação 4.5. As tensões encontradas após a terceira alocação de reativos são mostradas na Tabela 4.4

Tabela 4.4 - Tensões encontradas ao resolver o fluxo de carga após alocação de reativos do sistema W\&H6

\begin{tabular}{|c|c|c|c|}
\hline Barra & Tipo & Tensão (p.u.) & $\Delta$ Q (p.u.) \\
\hline 1 & V $\theta$ & 1,0500 & - \\
\hline 2 & PV & 1,1000 & - \\
\hline 3 & PQ & 0,9502 & 0,5017 \\
\hline 4 & PQ & 1,0069 & 0,0000 \\
\hline 5 & PQ & 0,9500 & 0,2081 \\
\hline 6 & PQ & 0,9734 & 0,2247 \\
\hline
\end{tabular}


A evolução dos estados resultantes a cada etapa da resolução é mostrada na Figura 4.1. Pode ser observado que após 3 alocações todas as tensões ficaram dentro dos limites estabelecidos.

É interessante notar que, apesar da barra 4 estar com a tensão abaixo do limite, não foi alocado nenhum reativo nesta barra. Isto pode se entendido analisando a matriz sensibilidade. No caso os termos $S_{21}$ e $S_{22}$, que mostram a variação da tensão na barra 4 com uma alocação na barra e e na própria barra 4, tem quase o mesmo valor. Então, para a correção da tensão na barra 4 , é mais interessante alocar reativos na barra 3, uma vez que o efeito na barra 4 será praticamente o mesmo, mas com maior efeito na barra 3.

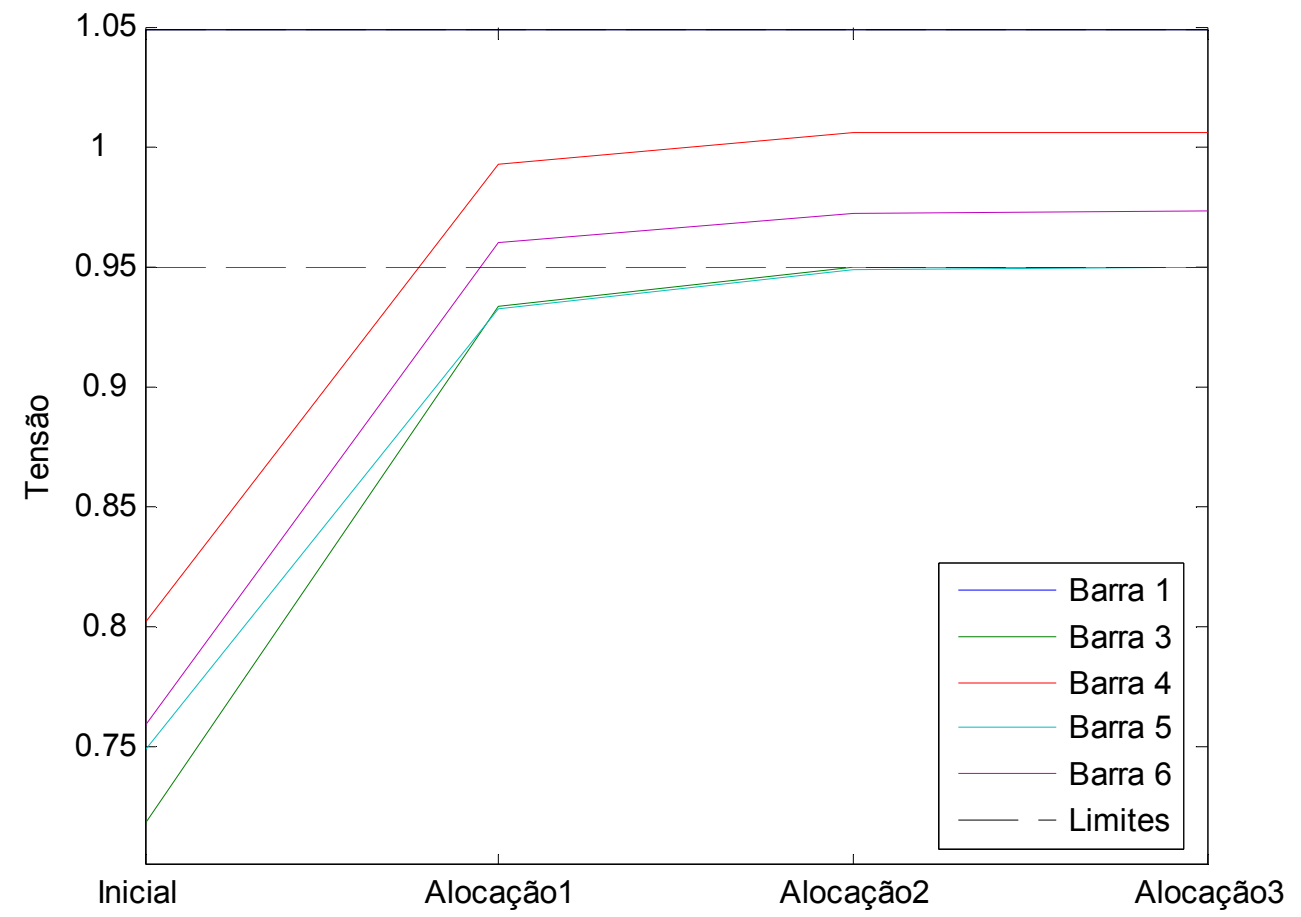

Figura 4.1 - Evolução das tensões no sistema W\&H6 após sucessivas alocações de reativos. 


\section{3 - Resultado do sistema IEEE - 14 modificado}

O sistema IEEE 14 barras está mostrado no apêndice A - 2. Ao rodar o fluxo de carga, o sistema mantinha todas as tensões dentro do limite. Para gerar uma situação com tensões abaixo do nível desejado, as cargas foram consideradas quatro vezes maiores. Para a situação de carga descrita, as tensões encontradas são mostradas na Tabela 4.5.

Tabela 4.5-Tensões encontradas ao resolver o fluxo de carga do sistema IEEE-14

\begin{tabular}{|c|c|c|}
\hline Barra & Tipo & Tensão (p.u.) \\
\hline 1 & V $\theta$ & 1,0600 \\
\hline 2 & PV & 1,0450 \\
\hline 3 & PV & 1,0100 \\
\hline 4 & PQ & 0,7957 \\
\hline 5 & PQ & 0,8106 \\
\hline 6 & PV & 1,0700 \\
\hline 7 & PQ & 0,8284 \\
\hline
\end{tabular}

\begin{tabular}{|c|c|c|}
\hline Barra & Tipo & Tensão (p.u.) \\
\hline 8 & PV & 1,0900 \\
\hline 9 & PQ & 0,7348 \\
\hline 10 & PQ & 0,7532 \\
\hline 11 & PQ & 0,8923 \\
\hline 12 & PQ & 0,9792 \\
\hline 13 & PQ & 0,9328 \\
\hline 14 & PQ & 0,7091 \\
\hline
\end{tabular}

Podemos observar que as tensões, em geral, estão bem abaixo do limite desejado, principalmente nas barras 9 e 14. As tensões e a quantidade de reativos alocados após a utilização do procedimento de otimização são encontradas na Tabela 4.6.

Tabela 4.6-Tensões encontradas após alocação de reativos no sistema IEEE-14

\begin{tabular}{|c|c|c|c|c|c|c|c|c|}
\hline Barra & Tipo & Tensão (p.u.) & $\Delta$ Q (p.u.) \\
\hline 1 & V $\theta$ & 1,0600 & - \\
\hline 2 & PV & 1,0450 & - \\
\hline 3 & PV & 1,0100 & - \\
\hline 4 & PQ & 0,9842 & 1,6628 \\
\hline 5 & PQ & 0,9895 & 1,0987 \\
\hline 6 & PV & 1,0700 & - \\
\hline 7 & PQ & 0,9875 & 0,0000 \\
\hline
\end{tabular}$\quad$\begin{tabular}{|c|c|c|c|}
\hline \\
\hline 10 & PV & 1,0900 & - \\
\hline 11 & PQ & 0,9629 & 0,5205 \\
\hline 12 & PQ & 0,9591 & 0,1337 \\
\hline 13 & PQ & 0,9991 & 0,0000 \\
\hline 14 & PQ & 0,9500 & 0,0000 \\
\hline
\end{tabular}

Como esperado, as tensões ficaram dentro dos limites desejados. Todas as tensões foram corrigidas 5 alocações de reativos. Embora fosse possível a alocação em nove barras, foi alocado reativo em apenas cinco barras sendo que foram concentrados nas barras 4 e 5 .

A evolução após cada alocação é mostrada na Figura 4.2: 


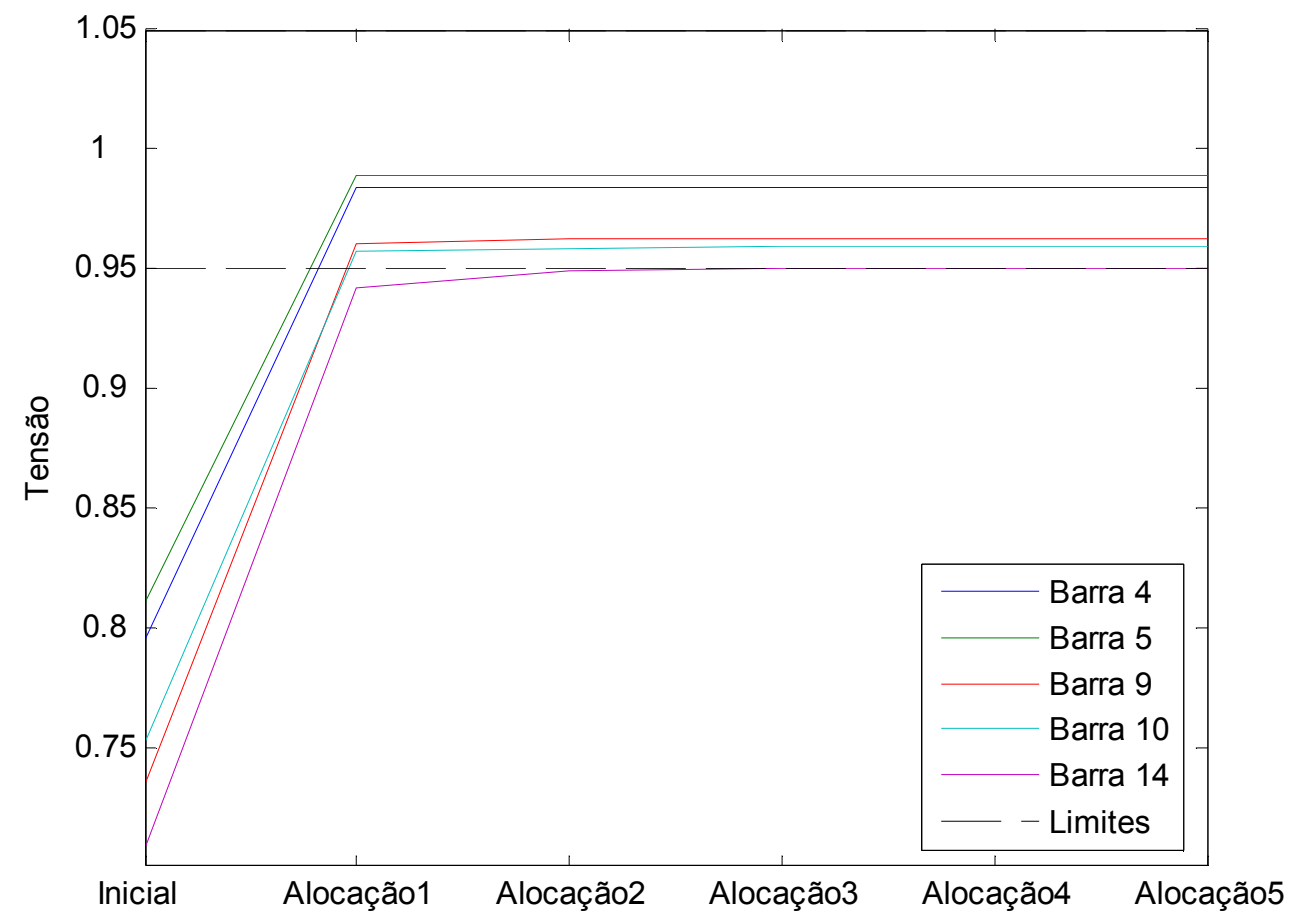

Figura 4.2 - Evolução das tensões no sistema IEEE-14 após sucessivas alocações de reativos.

\section{4 - Resultado do sistema IEEE- 30 modificado}

O sistema IEEE 30 barras está mostrado no apêndice A - 3. Para gerar maiores quedas de tensão, a carga foi multiplicada por 2,5. Este sistema se mostrou mais sensível ao aumento de carga, sendo que um aumento de 3 vezes já fazia o fluxo de carga não convergir.

As tensões encontradas após a resolução do problema de fluxo de carga são mostradas na Tabela 4.7. 
Tabela 4.7-Tensões encontradas ao resolver o fluxo de carga do sistema IEEE-30

\begin{tabular}{|c|c|c|}
\hline Barra & Tipo & Tensão (p.u.) \\
\hline 1 & V $\theta$ & 1,0600 \\
\hline 2 & PV & 1,0450 \\
\hline 3 & PQ & 0,9466 \\
\hline 4 & PQ & 0,9390 \\
\hline 5 & PV & 1,0100 \\
\hline 6 & PQ & 0,9584 \\
\hline 7 & PQ & 0,9557 \\
\hline 8 & PV & 1,0100 \\
\hline 9 & PQ & 0,9703 \\
\hline 10 & PQ & 0,9175 \\
\hline 11 & PV & 1,0820 \\
\hline 12 & PQ & 0,9684 \\
\hline 13 & PV & 1,0710 \\
\hline 14 & PQ & 0,9217 \\
\hline 15 & PQ & 0,9053 \\
\hline
\end{tabular}$\quad$\begin{tabular}{|c|c|c|}
\hline 18 & PQ & 0,9255 \\
\hline 19 & PQ & 0,9054 \\
\hline 20 & PQ & 0,8730 \\
\hline 21 & PQ & 0,8743 \\
\hline 22 & PQ & 0,8794 \\
\hline 23 & PQ & 0,8804 \\
\hline 24 & PQ & 0,8396 \\
\hline 25 & PQ & 0,8384 \\
\hline 26 & PQ & 0,7816 \\
\hline 27 & PQ & 0,8656 \\
\hline 28 & PQ & 0,9490 \\
\hline 29 & PQ & 0,7969 \\
\hline 30 & PQ & 0,7574 \\
\hline
\end{tabular}

Como nos casos anteriores, as tensões nas barras PQ estão bem abaixo do patamar desejado, sendo que, nas barras 26, 29 e 30, as tensões estão abaixo de 0,8 p.u. Após a correção, as tensões encontradas e os reativos alocados são mostrados na Tabela 4.8.

Tabela 4.8-Tensões encontradas ao resolver o fluxo de carga após alocação de reativos do sistema IEEE-30

\begin{tabular}{|c|c|c|c|c|c|c|c|}
\hline Barra & Tipo & Tensão (p.u.) & $\Delta$ Q (p.u.) \\
\hline 1 & V & 1,0600 & - \\
\hline 2 & PV & 1,0450 & - \\
\hline 3 & PQ & 0,9581 & 0,0000 \\
\hline 4 & PQ & 0,9527 & 0,0577 \\
\hline 5 & PV & 1,0100 & - \\
\hline 6 & PQ & 0,9703 & 0,0000 \\
\hline 7 & PQ & 0,9629 & 0,0000 \\
\hline 8 & PV & 1,0100 & - \\
\hline 9 & PQ & 1,0032 & 0,0000 \\
\hline 16 & Barra & Tipo & Tensão (p.u.) & $\Delta$ Q (p.u.) \\
\hline 17 & PQ & 0,9708 & 0,0000 \\
\hline 18 & PQ & 0,9613 & 0,0000 \\
\hline 19 & PQ & 0,9507 & 0,0155 \\
\hline 20 & PQ & 0,9546 & 0,1414 \\
\hline 21 & PQ & 0,9516 & 0,0000 \\
\hline 11 & PV & 0,9769 & 0,0000 \\
\hline 12 & PQ & 0,9681 & 0,0000 \\
\hline 13 & PV & 1,0710 & - & PQ & 0,9550 & 0,0000 \\
\hline 14 & PQ & 0,9681 & 0,0000 \\
\hline 15 & PQ & 0,9626 & 0,0000 \\
\hline
\end{tabular}$\quad$\begin{tabular}{|c|c|c|c|}
\hline 23 & PQ & 0,9501 & 0,0178 \\
\hline 24 & PQ & 0,9514 & 0,1992 \\
\hline 25 & PQ & 0,9687 & 0,0000 \\
\hline 26 & PQ & 0,9500 & 0,0712 \\
\hline 27 & PQ & 0,9875 & 0,0000 \\
\hline 28 & PQ & 0,9694 & 0,0000 \\
\hline 29 & PQ & 0,9562 & 0,0000 \\
\hline 30 & PQ & 0,9520 & 0,1393 \\
\hline
\end{tabular}

Como esperado, as tensões ficaram dentro dos limites desejados. A evolução das tensões após alocações sucessivas de reativos pode ser encontrada na figura 4.3. Nesse sistema só foram alocados reativos em 8 barras. Após a primeira alocação quatro barras ainda estavam fora do 
limite desejado. Após a terceira alocação, as tensões não variaram muito, mas só ficaram dentro do limite desejado após 6 alocações de reativos.

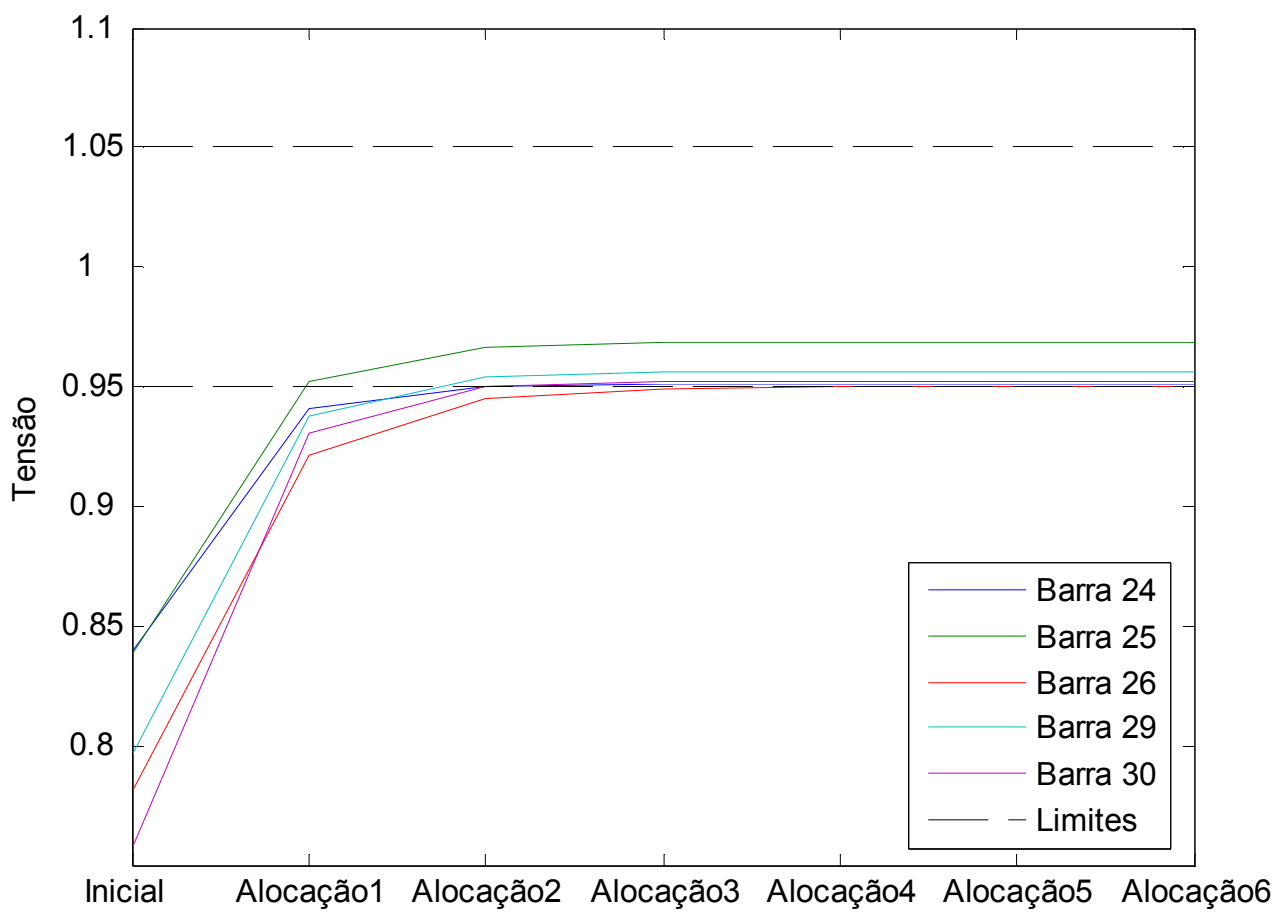

Figura 4.3 - Evolução das tensões no sistema IEEE-30 após sucessivas alocações de reativos. 


\section{CAPÍTULO 5 CONCLUSÃO}

O trabalho apresentou uma metodologia de correção das magnitudes das tensões em sistemas de potência. Foi elaborado um programa que implementa a proposta do trabalho. A utilização do programa se mostrou eficaz, resultando em sistemas com as tensões dentro dos limites especificados em todos os testes realizados.

Todos os casos foram simulados utilizando-se os métodos simplex e de ponto interior. Não houve diferença de resultados utilizando o método simplex ou o de ponto interior. Isto ocorre porque o ponto de mínimo está acontecendo devido a uma restrição, então não há diferença no resultado se, ao chegar a este ponto, é percorrido um caminho interior (método de ponto interior) ou somente pelos vértices (método simplex).

Podemos perceber que nem sempre são alocados reativos nas barras com a tensão mais baixa. Por exemplo, no caso do sistema com 30 barras, a barra 29, com a terceira menor tensão, não recebeu reativos e a barra 26 , com a segunda menor tensão, recebeu menos reativos que a barra 24, que tinha uma tensão maior. No teste com o sistema de 14 barras, algo parecido ocorreu. As maiores diferenças de tensão estavam nas barras 14 e 9 . No entanto, foram alocados mais reativos nas barras 4 e 5 . 


\section{BIBLIOGRAFIA}

CHICCO, G.; GROSS, G.; TAO, S. Allocation of the Reactive Power Support Requirements in Multitransaction Networks - IEEE TRANSACTIONS ON POWER SYSTEMS, VOL. 17, NO. 2, MAIO 2002

DANTZIG, G.B.; ORDEN A.; WOLFE P. Generalized Simplex Method for Minimizing a Linear from Under Linear Inequality Constraints Pacific Journal Math., Vol. 5, pp. 183-195.

GLOVER, J. D.; SARMA, M. Power System Analysis \& Design - Boston: PWS Publishing Company 1994.

GOH, S. H.; SAHA, T. K.; DONG, Z. Y. Optimal Reactive Power Allocation for Power System Transfer Capability Assessment disponível no sítio: http://ieeexplore.ieee.org/iel5/11204/36065/01709276.pdf, 2006

LIMA, R.T. Redes neurais artificiais aplicadas no controle de tensão de sistemas elétricos de potência - Rio de Janeiro: PUC-RIO 2007, disponível no sítio: http://www.maxwell.lambda.ele.puc-rio.br/cgibin/db2www/PRG_0651.D2W/SHOW?Mat=\&Sys $=\& N r=\& F u n=\& C d L i n P r g=p t \& C d N i v T e s$ $=\mathrm{ME} \& \mathrm{aux}=\mathrm{T} \& \mathrm{Cont}=11488: \mathrm{pt}$

MEHROTRA, S. On the Implementation of a Primal-Dual Interior Point Method SIAM Journal on Optimization, Vol. 2, pp. 575-601, 1992.

MONTICELli, A. J. Fluxo de Carga em Redes de Energia Elétrica - São Paulo: Editora Edgard Blücher LTDA 1983.

OLIVEIRA E. J.; FONTOURA R. M.; MARTINS N.;OLIVEIRA L. W.; PEREIRA J. L. R. Inclusão de restrições dinâmicas no problema de planejamento de potência reativa Sba Controle \& Automação vol.19 no.1 Natal 2008

RUGGiERO, M. A. G.; LOPES, V. L. R. Cálculo Numérico - Aspectos teóricos e Computacionais - São Paulo: PEARSON Makron books 2004 
SOUSA, T. Estudo de planejamento de reativos em sistemas elétricos de potência disponível no sítio: http://www.teses.usp.br/teses/disponiveis/3/3143/tde-07122006-144442/ - São Paulo USP 2003

SOUZA, A. M.; COSTA, C. E. U; COSTA, G. R. M. Alocação ótima de reativo utilizando matriz sensibilidade In: III Congresso Latino Americano de Geração e Transmissão de Energia Elétrica, 1997, Campos do Jordão - SP. Anais, 1997. p. 28-32.

UNIVERSITY OF WASHINGTON, College of Engineering, 14 Bus Power Flow Test Case disponível no sítio https://www.ee.washington.edu/research/pstca/pf14/pg tca14bus.htm/. Acesso em 13 de agosto de 2008.

UNIVERSITY OF WASHINGTON, College of Engineering, 30 Bus Power Flow Test Case disponível no sítio https://www.ee.washington.edu/research/pstca/pf30/ieee30cdf.txt/. Acesso em 13 de agosto de 2008. 


\section{APÊNDICES}




\section{APÊNDICE A - DADOS DOS SISTEMAS UTILIZADOS}

Os dados dos sistemas utilizados são mostrados a seguir. Todos os valores são dados em p.u.. $\mathrm{O}$ ângulo de referência é 0 nas barras V $\theta$.

\section{Sistema WARD\&HALE 6 barras:}

Os dados das barras e linhas são mostrados nas Tabelas A-1 e A-2. Um diagrama do sistema é mostrado na figura A-1. Este sistema foi retirado de SOUZA (2003).

Tabela A-1-Dados das barras do sistema W\&H6

\begin{tabular}{|c|c|c|c|c|c|c|}
\hline Barra & Tipo & $\mathrm{V}$ & $\begin{array}{c}\mathrm{P} \\
\text { Gerado }\end{array}$ & $\begin{array}{c}\text { Q } \\
\text { Gerado }\end{array}$ & P carga & Q Carga \\
\hline 1 & $\mathrm{~V} \theta$ & 1,050 & 0,00 & 0,00 & 0,000 & 0,000 \\
\hline 2 & $\mathrm{PV}$ & 1,100 & 0,50 & 0,00 & 0,000 & 0,000 \\
\hline 3 & $\mathrm{PQ}$ & - & 0,00 & 0,00 & 0,825 & 0,195 \\
\hline 4 & $\mathrm{PQ}$ & - & 0,00 & 0,00 & 0,000 & 0,000 \\
\hline 5 & $\mathrm{PQ}$ & - & 0,00 & 0,00 & 0,450 & 0,270 \\
\hline 6 & $\mathrm{PQ}$ & - & 0,00 & 0,00 & 0,750 & 0,075 \\
\hline
\end{tabular}

Tabela A-2-Dados das linhas do sistema W\&H6

\begin{tabular}{|c|c|c|c|c|}
\hline From & To & Resistência & Reatância & Tap \\
\hline 1 & 6 & 0,123 & 0,518 & - \\
\hline 1 & 4 & 0,080 & 0,370 & - \\
\hline 4 & 6 & 0,097 & 0,407 & - \\
\hline 5 & 6 & 0,000 & 0,300 & 1,025 \\
\hline 5 & 2 & 0,282 & 0,640 & - \\
\hline 2 & 3 & 0,723 & 1,050 & - \\
\hline 3 & 4 & 0,000 & 0,133 & 1,1 \\
\hline
\end{tabular}




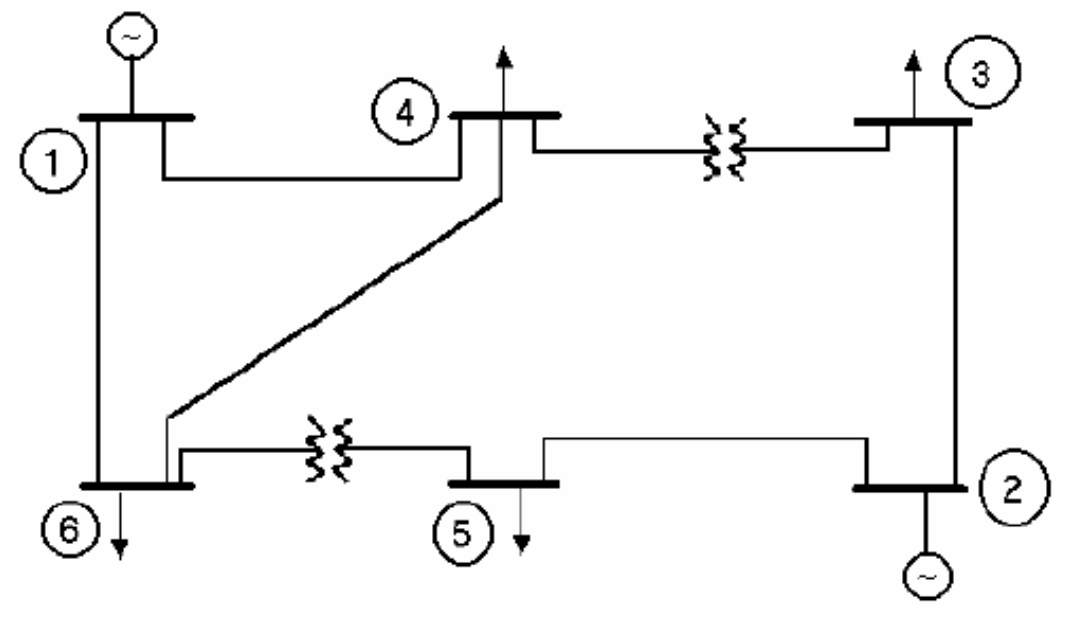

Figura A-1 - Sistema Ward\&Hale de 6 barras 


\section{Sistema IEEE-14:}

Os dados das barras e linhas são mostrados nas Tabelas A-3 e A-4. Um diagrama do sistema é mostrado na figura A-2. Os dados deste sistema foram retirados do sítio da Universidade de Washington citado na bibliografia.

Tabela A-3-Dados das barras do sistema IEEE-14

\begin{tabular}{|c|c|c|c|c|c|c|c|}
\hline Barra & Tipo & $\mathrm{V}$ & $\begin{array}{c}\mathrm{P} \\
\text { Gerado }\end{array}$ & $\begin{array}{c}\mathrm{Q} \\
\text { Gerado }\end{array}$ & $\mathrm{P}$ carga & Q Carga & $B^{\text {sh }}$ \\
\hline 1 & $\mathrm{PV}$ & 1,060 & 2,320 & 0,000 & 0,000 & 0,000 & - \\
\hline 2 & $\mathrm{~V} \theta$ & 1,045 & 0,400 & $-0,424$ & 0,868 & 0,508 & - \\
\hline 3 & $\mathrm{PV}$ & 1,010 & 0,000 & 0,000 & 3,768 & 0,760 & - \\
\hline 4 & $\mathrm{PQ}$ & - & 0,000 & 0,000 & 1,912 & 0,000 & - \\
\hline 5 & $\mathrm{PQ}$ & - & 0,000 & 0,000 & 0,304 & 0,064 & - \\
\hline 6 & $\mathrm{PV}$ & 1,070 & 0,000 & 0,000 & 0,448 & 0,300 & - \\
\hline 7 & $\mathrm{PQ}$ & - & 0,000 & 0,000 & 0,000 & 0,000 & - \\
\hline 8 & $\mathrm{PV}$ & 1,090 & 0,000 & 0,000 & 0,000 & 0,000 & - \\
\hline 9 & $\mathrm{PQ}$ & - & 0,000 & 0,000 & 1,180 & 0,664 & 0,190 \\
\hline 10 & $\mathrm{PQ}$ & - & 0,000 & 0,000 & 0,360 & 0,232 & - \\
\hline 11 & $\mathrm{PQ}$ & - & 0,000 & 0,000 & 0,140 & 0,072 & - \\
\hline 12 & $\mathrm{PQ}$ & - & 0,000 & 0,000 & 0,244 & 0,064 & - \\
\hline 13 & $\mathrm{PQ}$ & - & 0,000 & 0,000 & 0,540 & 0,232 & - \\
\hline 14 & $\mathrm{PQ}$ & - & 0,000 & 0,000 & 0,596 & 0,200 & - \\
\hline
\end{tabular}

Tabela A-4-Dados das linhas do sistema IEEE-14

\begin{tabular}{|c|c|c|c|c|c|}
\hline From & To & Resistência & Reatância & $\begin{array}{c}\text { Line } \\
\text { Charging }\end{array}$ & Tap \\
\hline 1 & 2 & 0,01938 & 0,05917 & 0,0528 & - \\
\hline 1 & 5 & 0,05403 & 0,22304 & 0,0492 & - \\
\hline 2 & 3 & 0,04699 & 0,19797 & 0,0438 & - \\
\hline 2 & 4 & 0,05811 & 0,17632 & 0,0374 & - \\
\hline 2 & 5 & 0,05695 & 0,17388 & 0,034 & - \\
\hline 3 & 4 & 0,06701 & 0,17103 & 0,0346 & - \\
\hline 4 & 5 & 0,01335 & 0,04211 & 0,0128 & - \\
\hline 4 & 7 & 0,00000 & 0,20912 & 0,0000 & 0,978 \\
\hline 4 & 9 & 0,00000 & 0,55618 & 0,0000 & 0,969 \\
\hline 5 & 6 & 0,00000 & 0,25202 & 0,0000 & 0,932 \\
\hline 6 & 11 & 0,09498 & 0,19890 & 0,0000 & - \\
\hline 6 & 12 & 0,12291 & 0,25581 & 0,0000 & - \\
\hline 6 & 13 & 0,06615 & 0,13027 & 0,0000 & - \\
\hline 7 & 8 & 0,00000 & 0,17615 & 0,0000 & - \\
\hline 7 & 9 & 0,00000 & 0,11001 & 0,0000 & - \\
\hline 9 & 10 & 0,03181 & 0,08450 & 0,0000 & - \\
\hline 9 & 14 & 0,12711 & 0,27038 & 0,0000 & - \\
\hline 10 & 11 & 0,08205 & 0,19207 & 0,0000 & - \\
\hline 12 & 13 & 0,22092 & 0,19988 & 0,0000 & - \\
\hline 13 & 14 & 0,17093 & 0,34802 & 0,0000 & - \\
\hline
\end{tabular}




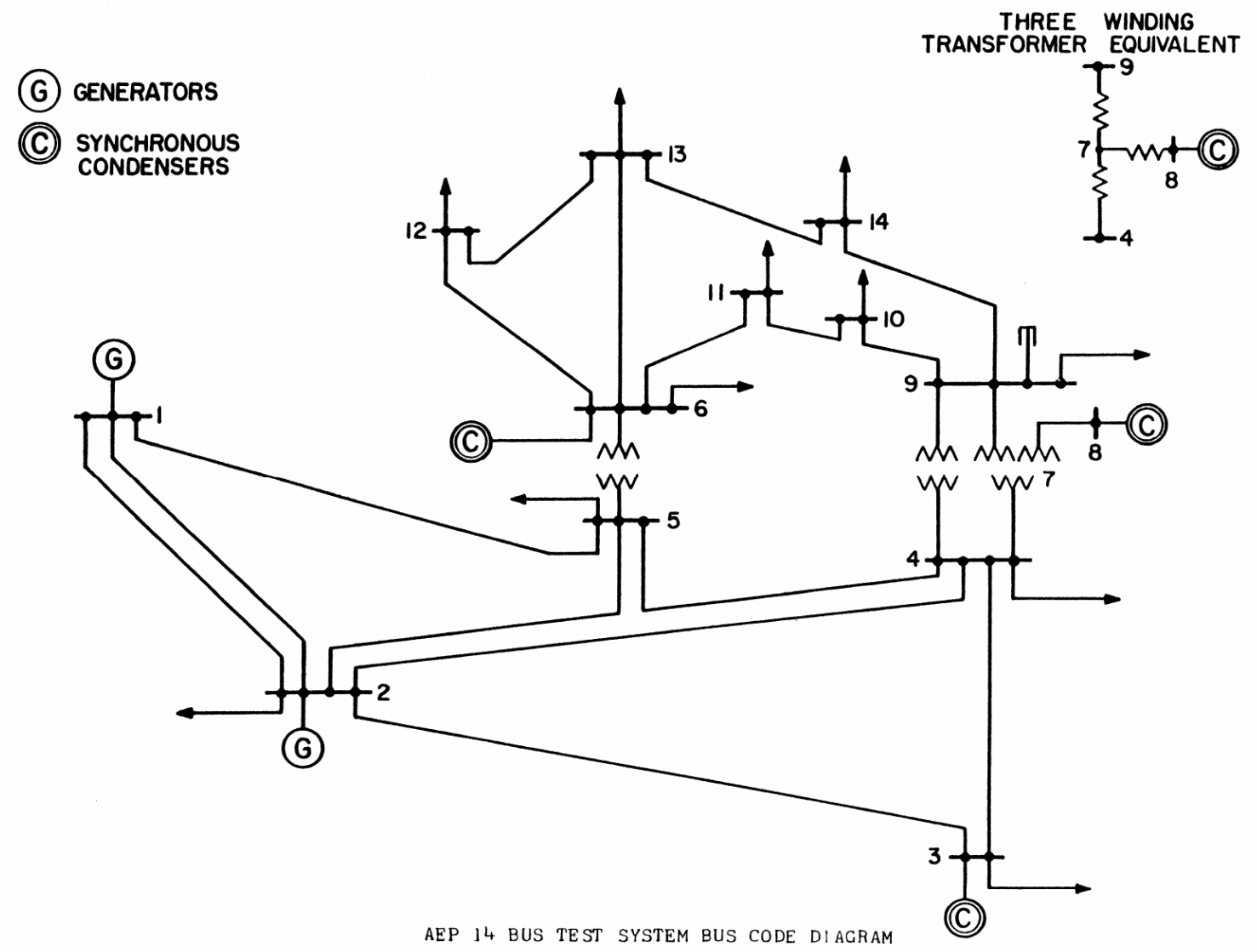

Figura A-2 - Sistema IEEE-14 


\section{Sistema IEEE-30:}

Os dados das barras e linhas são mostrados nas Tabelas A-5 e A-6. Um diagrama do sistema é mostrado na figura A-3. Os dados deste sistema foram retirados do sítio da Universidade de Washington citado na bibliografia.

Tabela A-5-Dados das barras do sistema IEEE-30

\begin{tabular}{|c|c|c|c|c|c|c|c|}
\hline Barra & Tipo & $\mathrm{V}$ & $\begin{array}{c}\mathrm{P} \\
\text { Gerado }\end{array}$ & $\begin{array}{c}\text { Q } \\
\text { Gerado }\end{array}$ & P carga & Q Carga & $B^{\text {sh }}$ \\
\hline 1 & $\mathrm{~V} \theta$ & 1,060 & 2.602 & -0.161 & 0.0000 & 0.0000 & - \\
\hline 2 & $\mathrm{PV}$ & 1,045 & 0.400 & 0.500 & 0.5425 & 0.3175 & - \\
\hline 3 & $\mathrm{PQ}$ & - & 0.000 & 0.000 & 0.0600 & 0.0300 & - \\
\hline 4 & $\mathrm{PQ}$ & - & 0.000 & 0.000 & 0.1900 & 0.0400 & - \\
\hline 5 & $\mathrm{PV}$ & 1,010 & 0.000 & 0.370 & 2.3550 & 0.4750 & - \\
\hline 6 & $\mathrm{PQ}$ & - & 0.000 & 0.000 & 0.0000 & 0.0000 & - \\
\hline 7 & $\mathrm{PQ}$ & - & 0.000 & 0.000 & 0.5700 & 0.2725 & - \\
\hline 8 & $\mathrm{PV}$ & 1,010 & 0.000 & 0.373 & 0.7500 & 0.7500 & - \\
\hline 9 & $\mathrm{PQ}$ & - & 0.000 & 0.000 & 0.0000 & 0.0000 & - \\
\hline 10 & $\mathrm{PQ}$ & - & 0.000 & 0.000 & 0.1450 & 0.0500 & 0.190 \\
\hline 11 & $\mathrm{PV}$ & 1,082 & 0.000 & 0.162 & 0.0000 & 0.0000 & - \\
\hline 12 & $\mathrm{PQ}$ & - & 0.000 & 0.000 & 0.2800 & 0.1875 & - \\
\hline 13 & $\mathrm{PV}$ & 1,071 & 0.000 & 0.106 & 0.0000 & 0.0000 & - \\
\hline 14 & $\mathrm{PQ}$ & - & 0.000 & 0.000 & 0.1550 & 0.0400 & - \\
\hline 15 & $\mathrm{PQ}$ & - & 0.000 & 0.000 & 0.2050 & 0.0625 & - \\
\hline 16 & $\mathrm{PQ}$ & - & 0.000 & 0.000 & 0.0875 & 0.0450 & - \\
\hline 17 & $\mathrm{PQ}$ & - & 0.000 & 0.000 & 0.2250 & 0.1450 & - \\
\hline 18 & $\mathrm{PQ}$ & - & 0.000 & 0.000 & 0.0800 & 0.0225 & - \\
\hline 19 & $\mathrm{PQ}$ & - & 0.000 & 0.000 & 0.2375 & 0.0850 & - \\
\hline 20 & $\mathrm{PQ}$ & - & 0.000 & 0.000 & 0.0550 & 0.0175 & - \\
\hline 21 & $\mathrm{PQ}$ & - & 0.000 & 0.000 & 0.4375 & 0.2800 & - \\
\hline 22 & $\mathrm{PQ}$ & - & 0.000 & 0.000 & 0.0000 & 0.0000 & - \\
\hline 23 & $\mathrm{PQ}$ & - & 0.000 & 0.000 & 0.0800 & 0.0400 & - \\
\hline 24 & $\mathrm{PQ}$ & - & 0.000 & 0.000 & 0.2175 & 0.1675 & 0.043 \\
\hline 25 & $\mathrm{PQ}$ & - & 0.000 & 0.000 & 0.0000 & 0.0000 & - \\
\hline 26 & $\mathrm{PQ}$ & - & 0.000 & 0.000 & 0.0875 & 0.0575 & - \\
\hline 27 & $\mathrm{PQ}$ & - & 0.000 & 0.000 & 0.0000 & 0.0000 & - \\
\hline 28 & $\mathrm{PQ}$ & - & 0.000 & 0.000 & 0.0000 & 0.0000 & - \\
\hline 29 & $\mathrm{PQ}$ & - & 0.000 & 0.000 & 0.0600 & 0.0225 & - \\
\hline 30 & $\mathrm{PQ}$ & - & 0.000 & 0.000 & 0.2650 & 0.0475 & - \\
\hline & & & & & & & \\
\hline 12 & & & - \\
\hline
\end{tabular}


Tabela A-6-Dados das linhas do sistema IEEE-30

\begin{tabular}{|c|c|c|c|c|c|}
\hline From & To & Resistência & Reatância & $\begin{array}{c}\text { Line } \\
\text { Charging }\end{array}$ & Tap \\
\hline 1 & 2 & 0.0192 & 0.0575 & 0.1056 & - \\
\hline 1 & 3 & 0.0452 & 0.1652 & 0.0816 & - \\
\hline 2 & 4 & 0.0570 & 0.1737 & 0.0736 & - \\
\hline 3 & 4 & 0.0132 & 0.0379 & 0.0168 & - \\
\hline 2 & 5 & 0.0472 & 0.1983 & 0.0836 & - \\
\hline 2 & 6 & 0.0581 & 0.1763 & 0.0748 & - \\
\hline 4 & 6 & 0.0119 & 0.0414 & 0.0180 & - \\
\hline 5 & 7 & 0.0460 & 0.1160 & 0.0408 & - \\
\hline 6 & 7 & 0.0267 & 0.0820 & 0.0340 & - \\
\hline 6 & 8 & 0.0120 & 0.0420 & 0.0180 & - \\
\hline 6 & 9 & 0.0000 & 0.2080 & 0.0000 & 0.978 \\
\hline 6 & 10 & 0.0000 & 0.5560 & 0.0000 & 0.969 \\
\hline 9 & 11 & 0.0000 & 0.2080 & 0.0000 & - \\
\hline 9 & 10 & 0.0000 & 0.1100 & 0.0000 & - \\
\hline 4 & 12 & 0.0000 & 0.2560 & 0.0000 & 0.932 \\
\hline 12 & 13 & 0.0000 & 0.1400 & 0.0000 & - \\
\hline 12 & 14 & 0.1231 & 0.2559 & 0.0000 & - \\
\hline 12 & 15 & 0.0662 & 0.1304 & 0.0000 & - \\
\hline 12 & 16 & 0.0945 & 0.1987 & 0.0000 & - \\
\hline 14 & 15 & 0.2210 & 0.1997 & 0.0000 & - \\
\hline 16 & 17 & 0.0524 & 0.1923 & 0.0000 & - \\
\hline 15 & 18 & 0.1073 & 0.2185 & 0.0000 & - \\
\hline 18 & 19 & 0.0639 & 0.1292 & 0.0000 & - \\
\hline 19 & 20 & 0.0340 & 0.0680 & 0.0000 & - \\
\hline 10 & 20 & 0.0936 & 0.2090 & 0.0000 & - \\
\hline 10 & 17 & 0.0324 & 0.0845 & 0.0000 & - \\
\hline 10 & 21 & 0.0348 & 0.0749 & 0.0000 & - \\
\hline 10 & 22 & 0.0727 & 0.1499 & 0.0000 & - \\
\hline 21 & 22 & 0.0116 & 0.0236 & 0.0000 & - \\
\hline 15 & 23 & 0.1000 & 0.2020 & 0.0000 & - \\
\hline 22 & 24 & 0.1150 & 0.1790 & 0.0000 & - \\
\hline 23 & 24 & 0.1320 & 0.2700 & 0.0000 & - \\
\hline 24 & 25 & 0.1885 & 0.3292 & 0.0000 & - \\
\hline 25 & 26 & 0.2544 & 0.3800 & 0.0000 & - \\
\hline 25 & 27 & 0.1093 & 0.2087 & 0.0000 & - \\
\hline 28 & 27 & 0.0000 & 0.3960 & 0.0000 & 0.968 \\
\hline 27 & 29 & 0.2198 & 0.4153 & 0.0000 & - \\
\hline 27 & 30 & 0.3202 & 0.6027 & 0.0000 & - \\
\hline 29 & 30 & 0.2399 & 0.4533 & 0.0000 & - \\
\hline 8 & 28 & 0.0636 & 0.2000 & 0.0856 & - \\
\hline 6 & 28 & 0.0169 & 0.0599 & 0.0260 & - \\
\hline
\end{tabular}




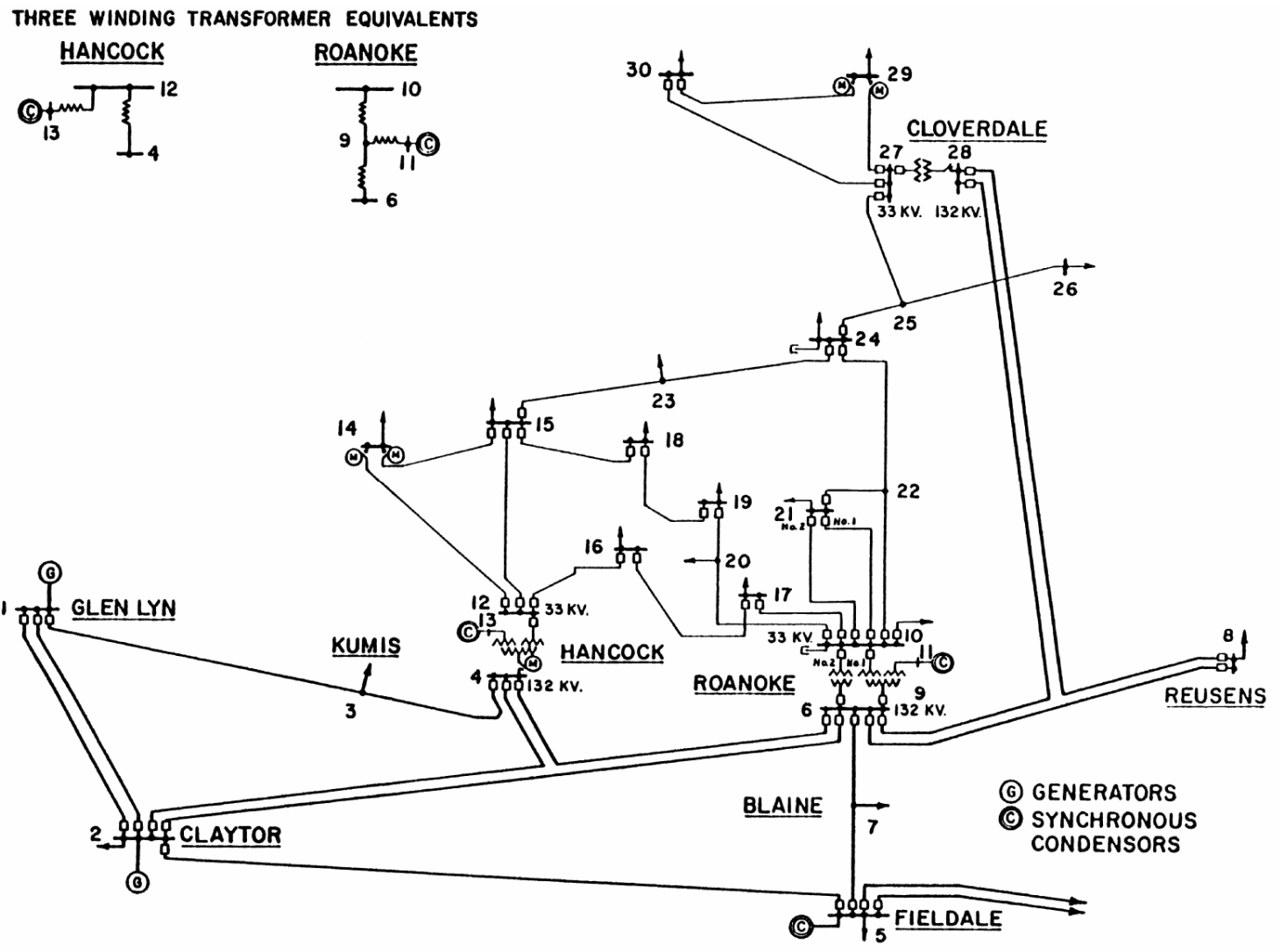

Figura A-3 -Sistema IEEE-30 


\section{APÊNDICE B - CÓDIGO DO PROGRAMA}

Os comentários são precedidos de \%.

\section{Arquivo de entrada:}

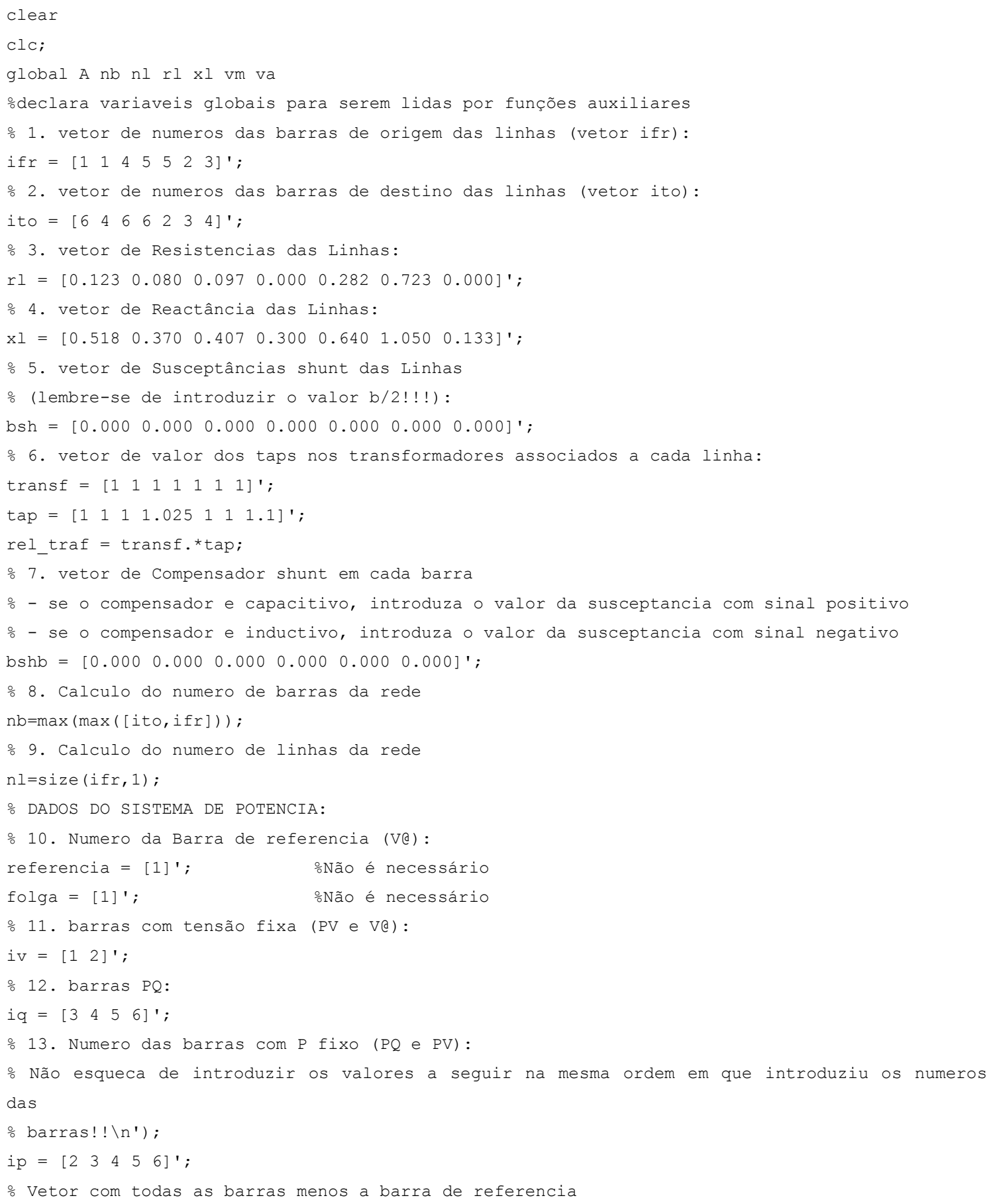




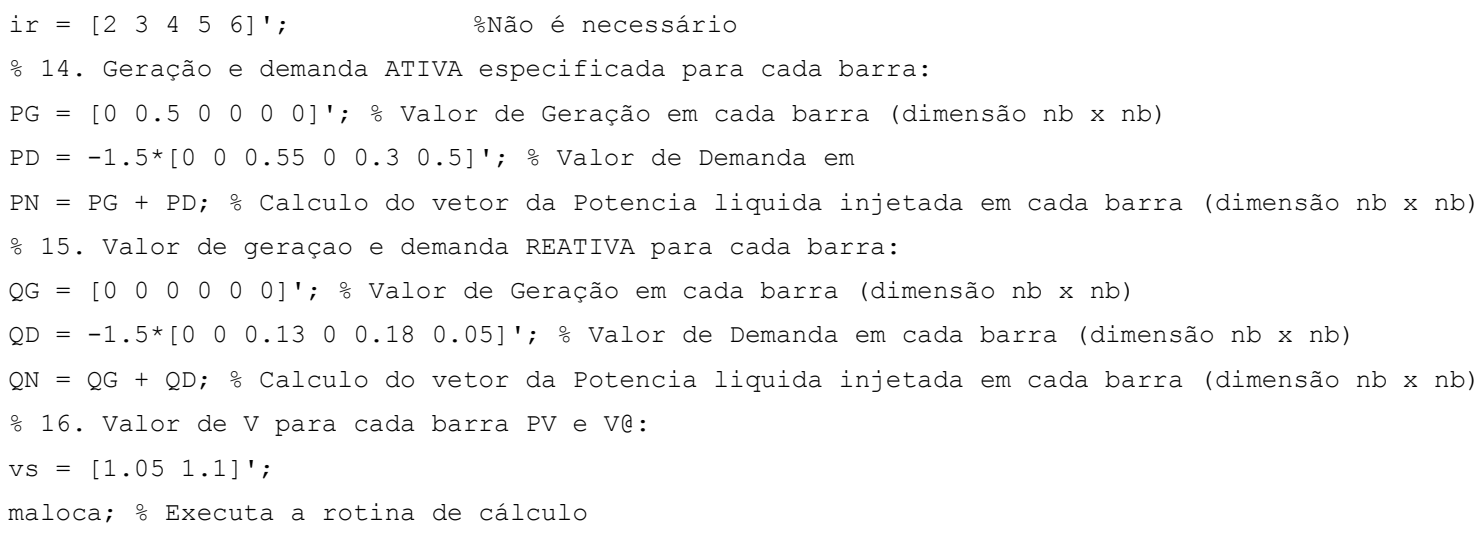

\section{Base do programa (maloca.m):}

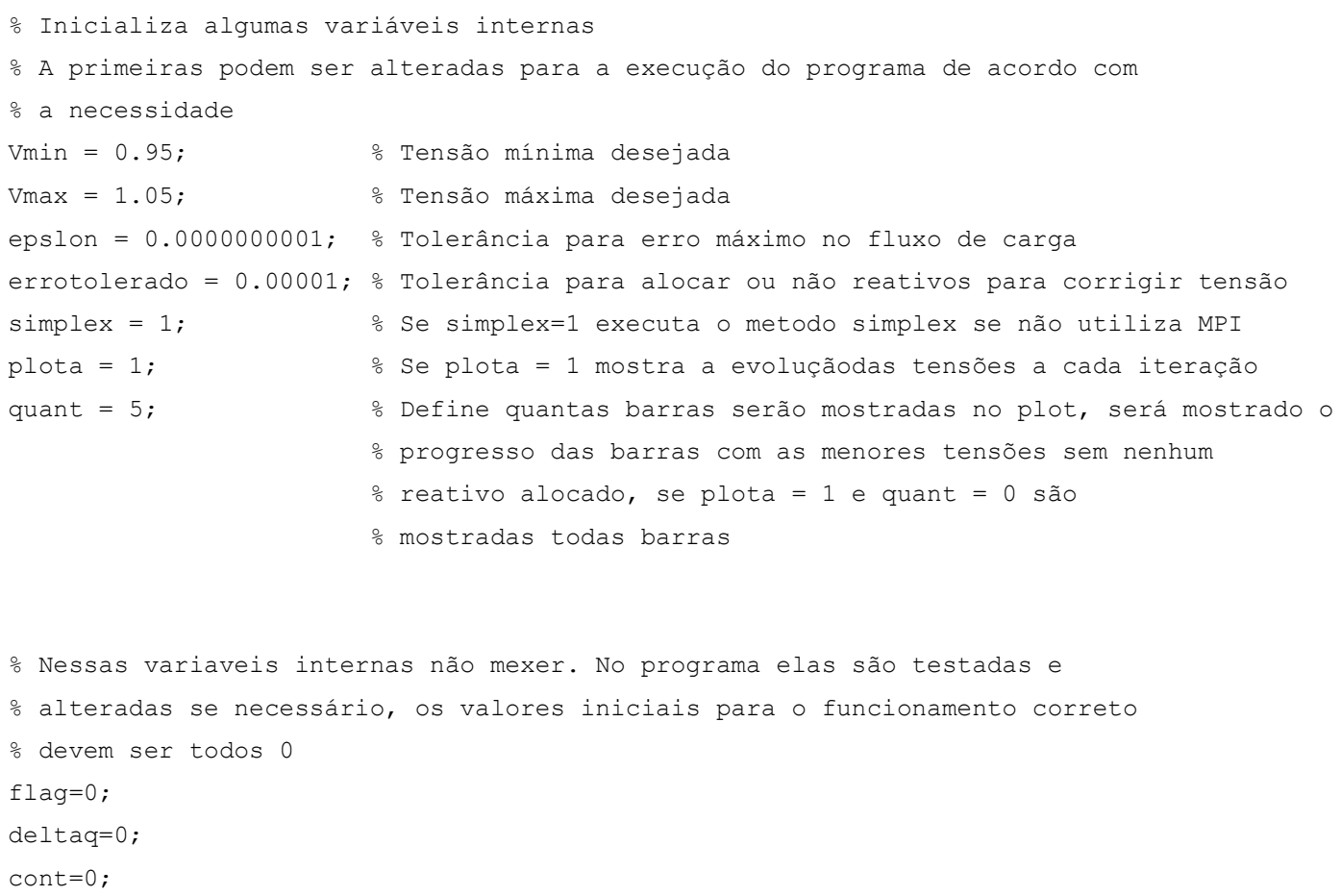




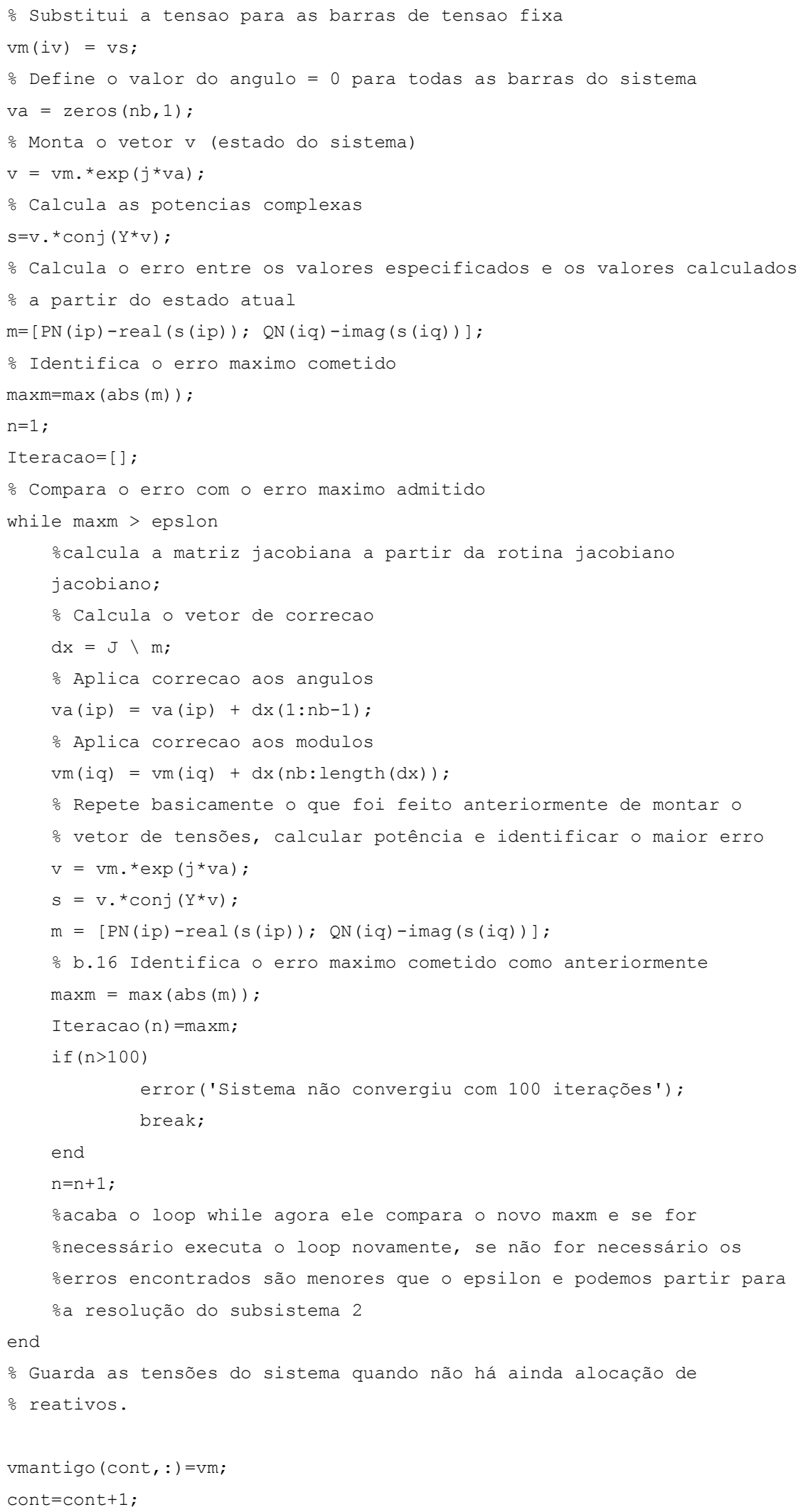




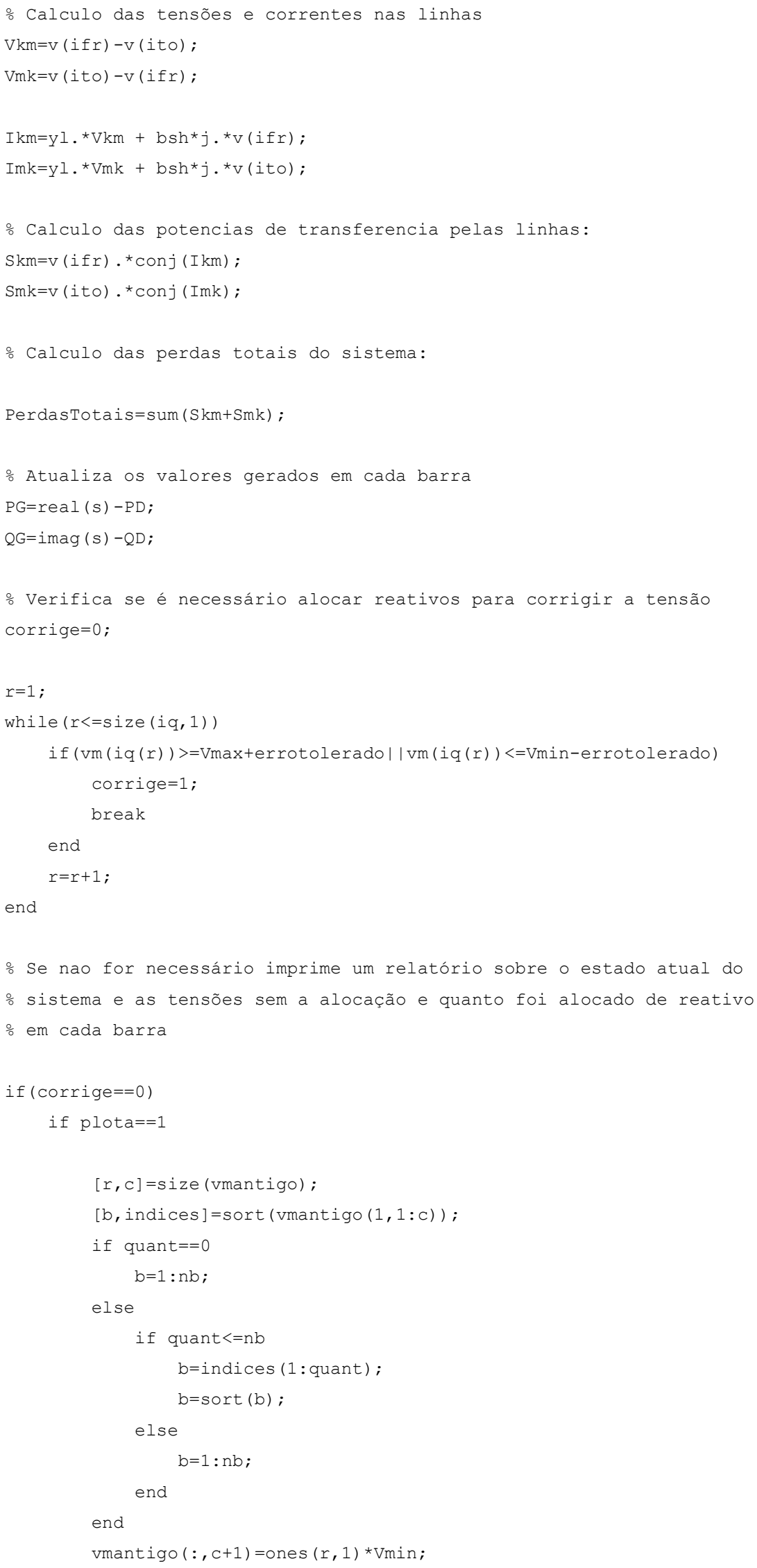




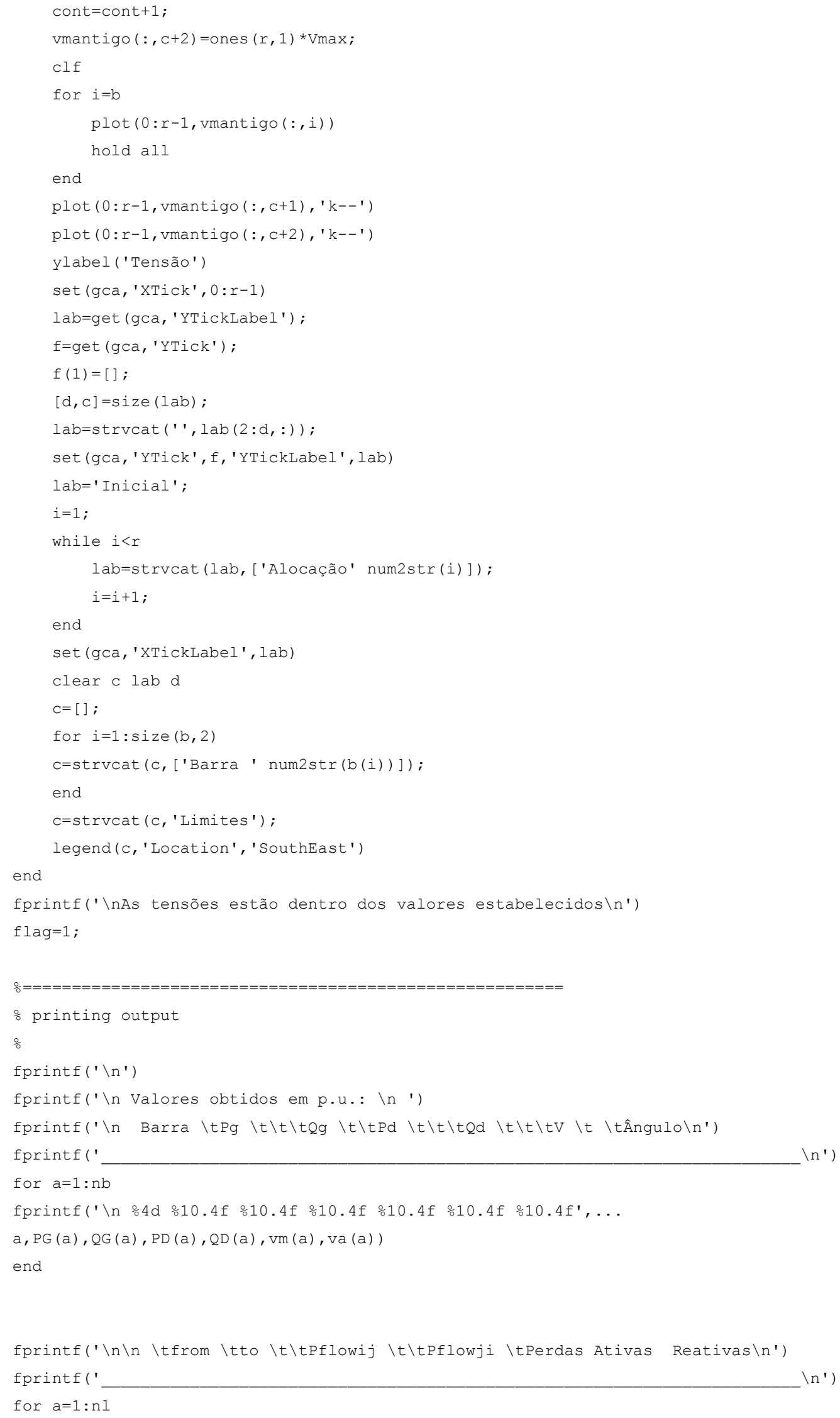




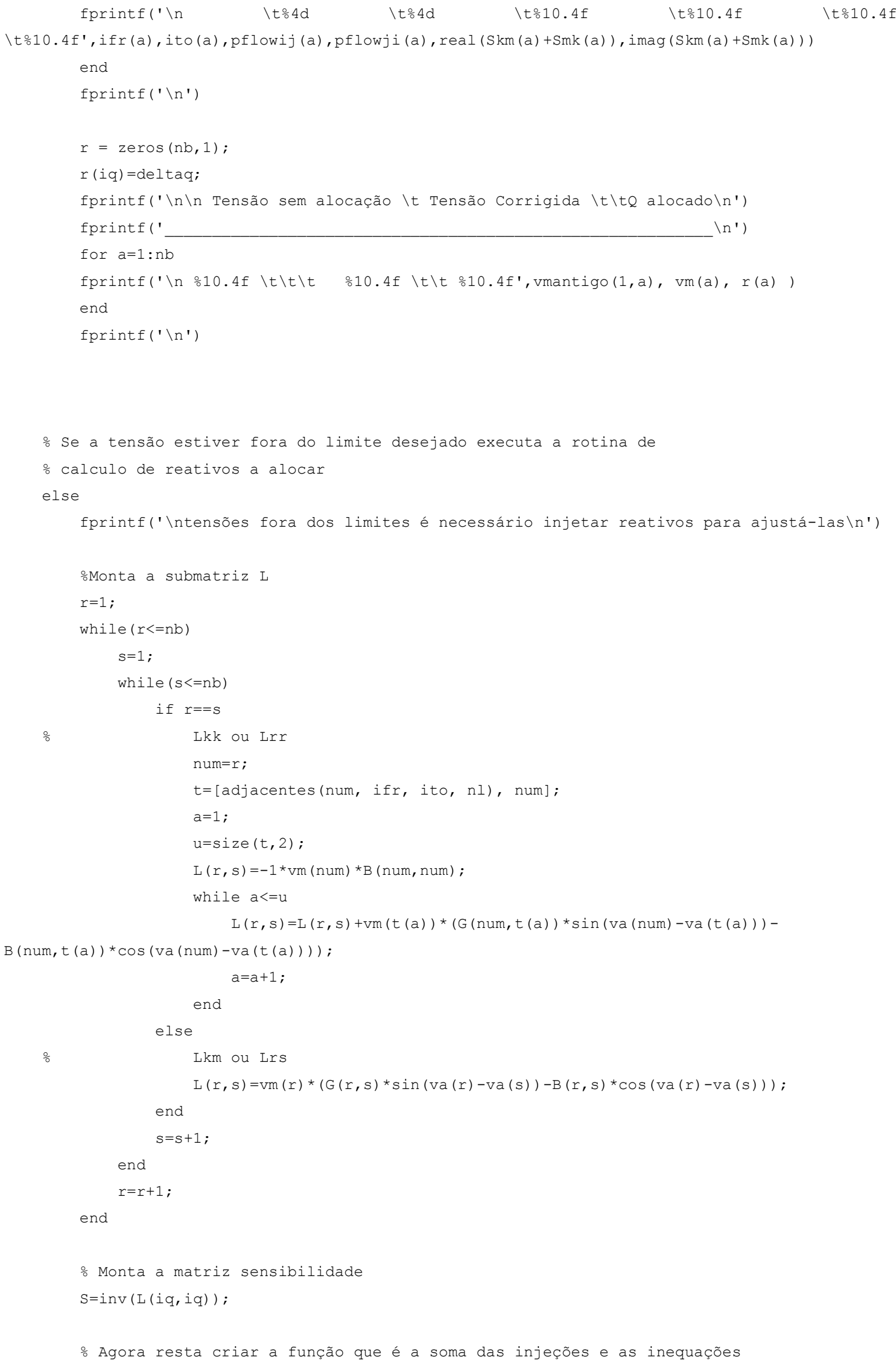




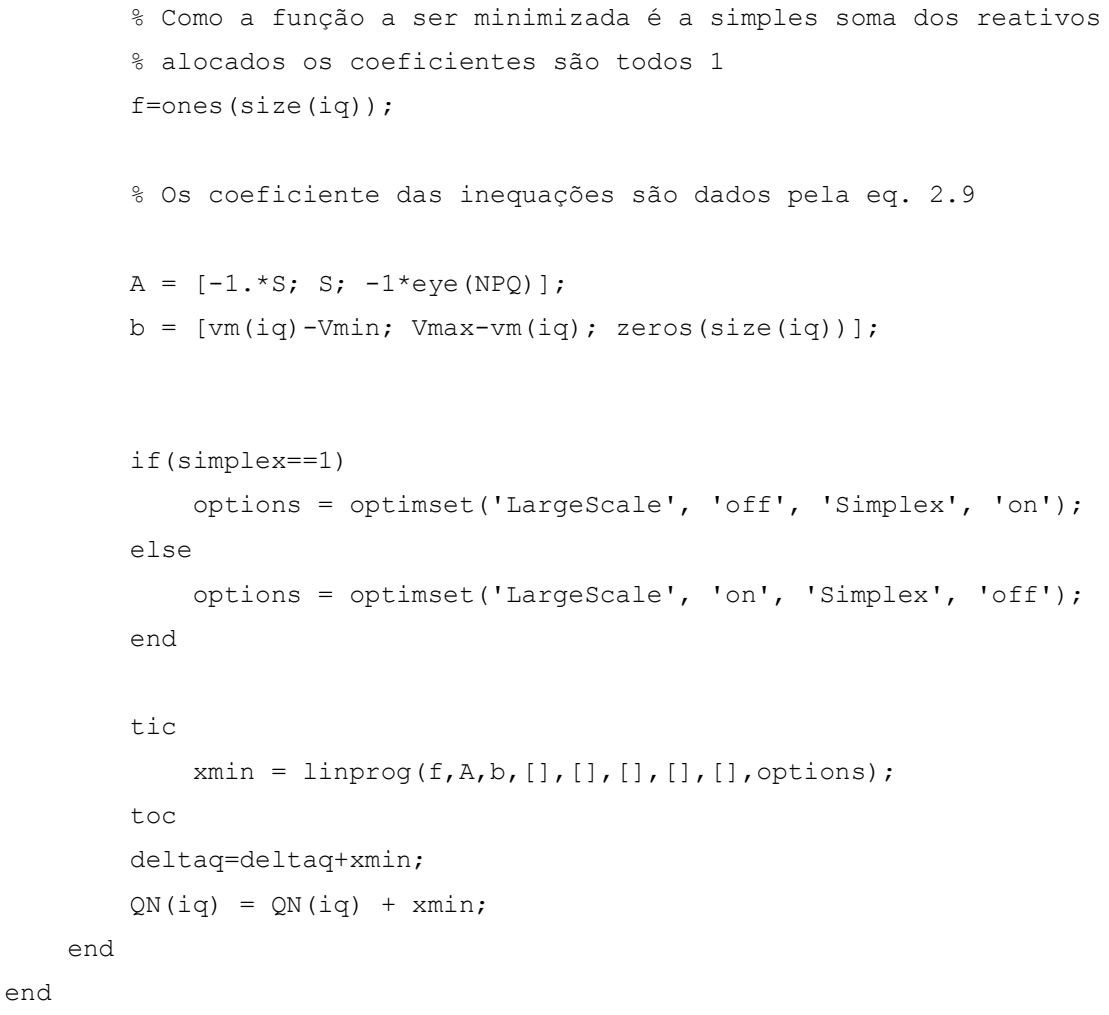

\section{Funções/Rotinas auxiliares:}

- Cálculo da matriz admitância (madmitancia.m):

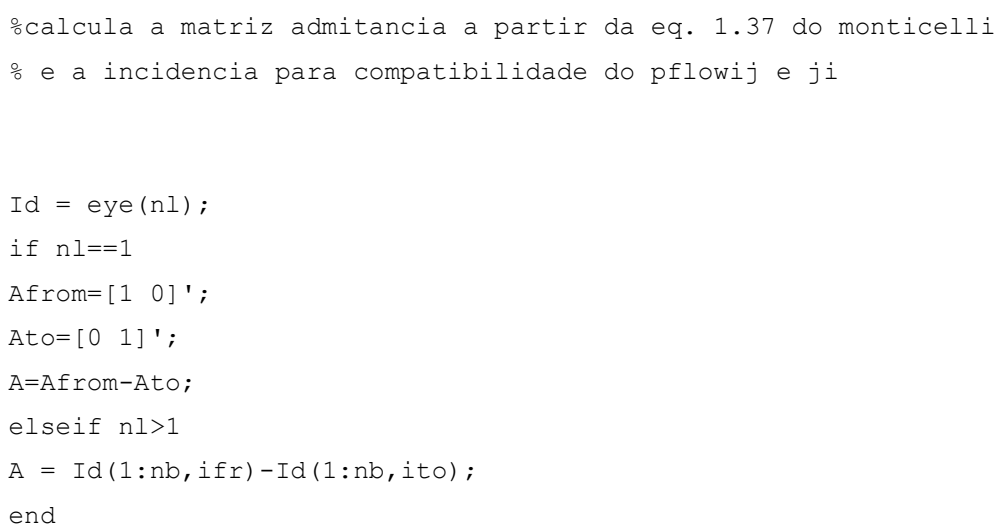




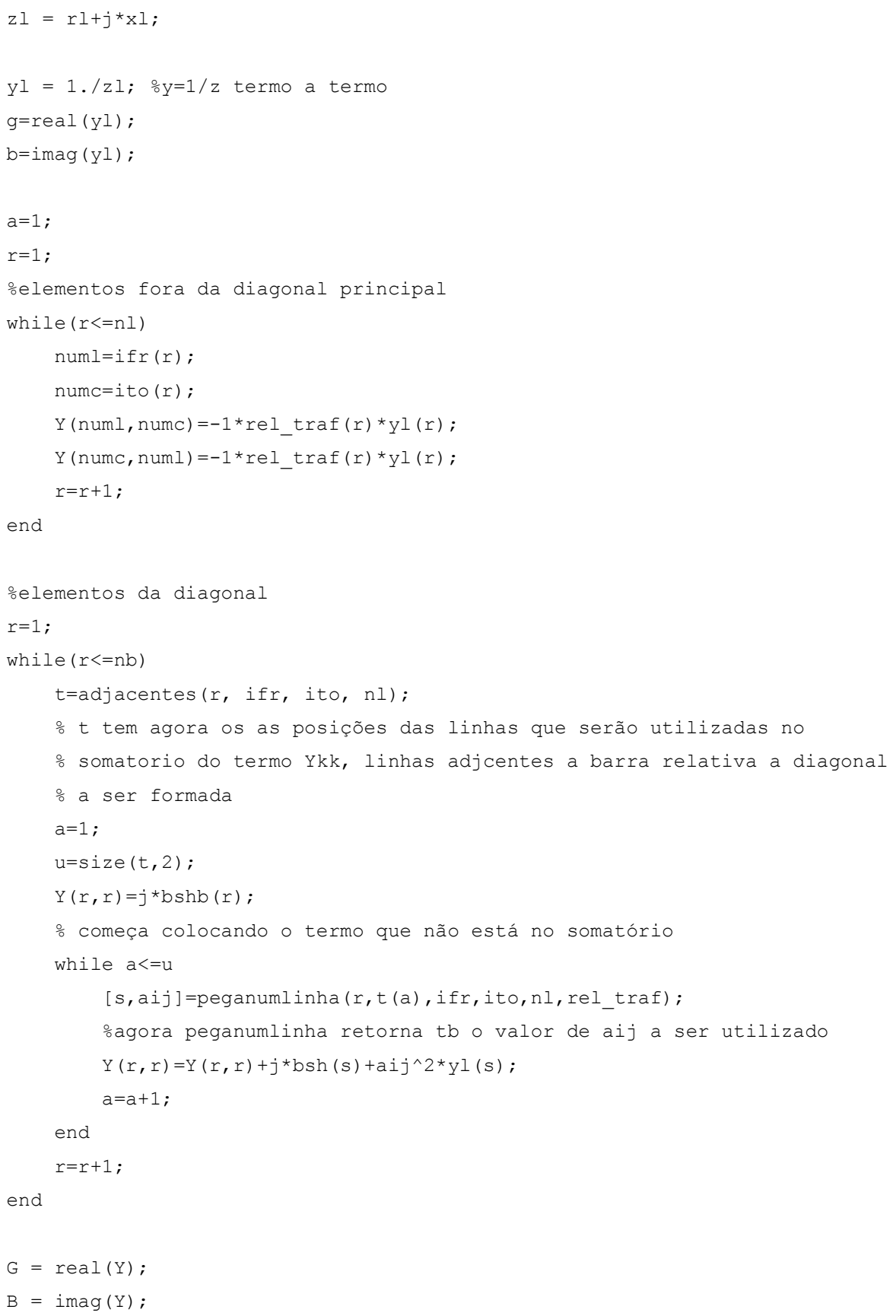

- Cálculo da matriz jacobiana (jacobiano.m):

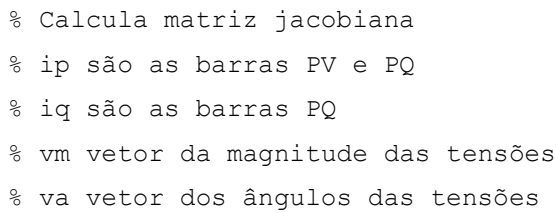




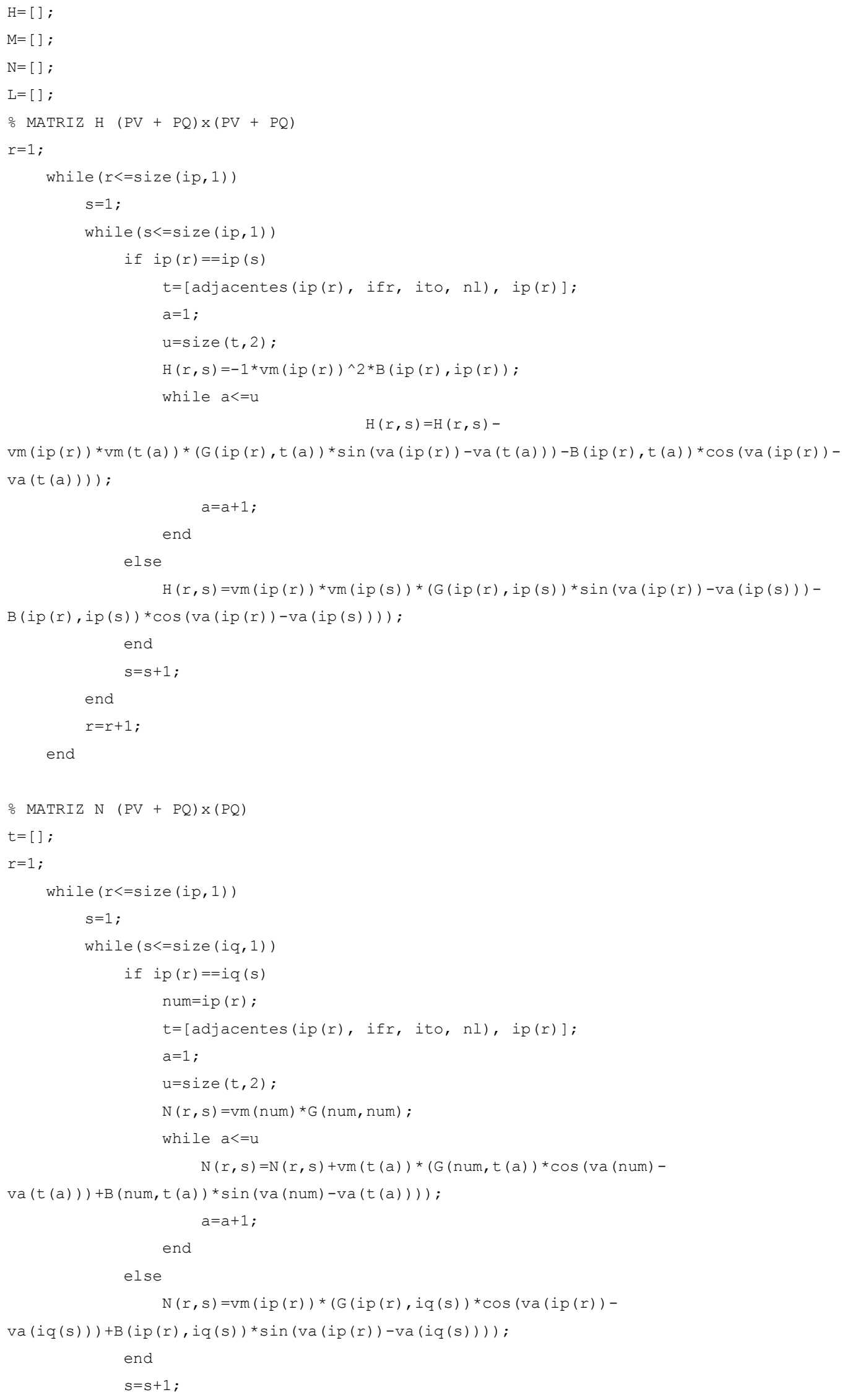




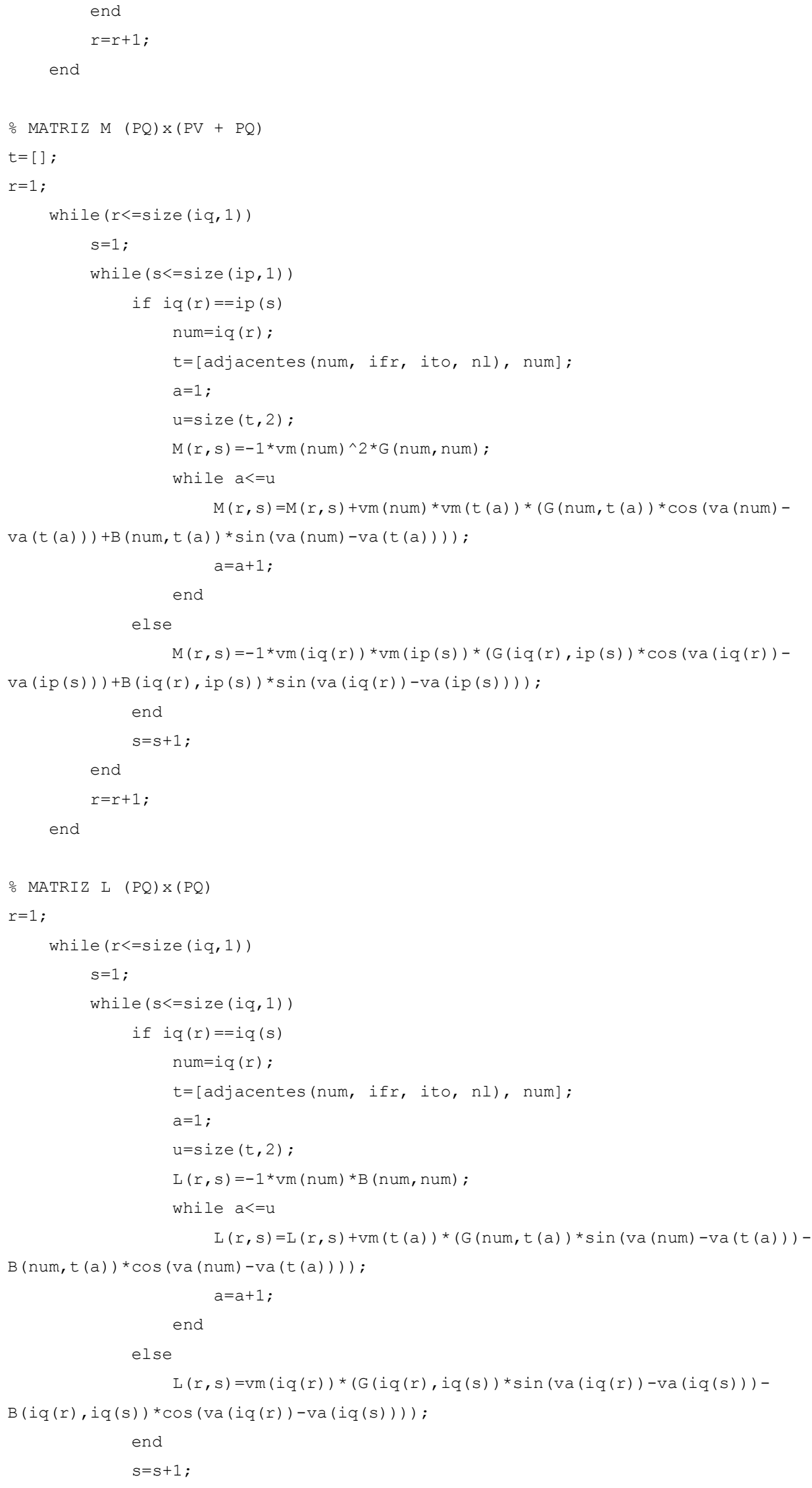




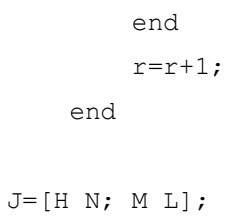

\section{- Função adjacentes:}

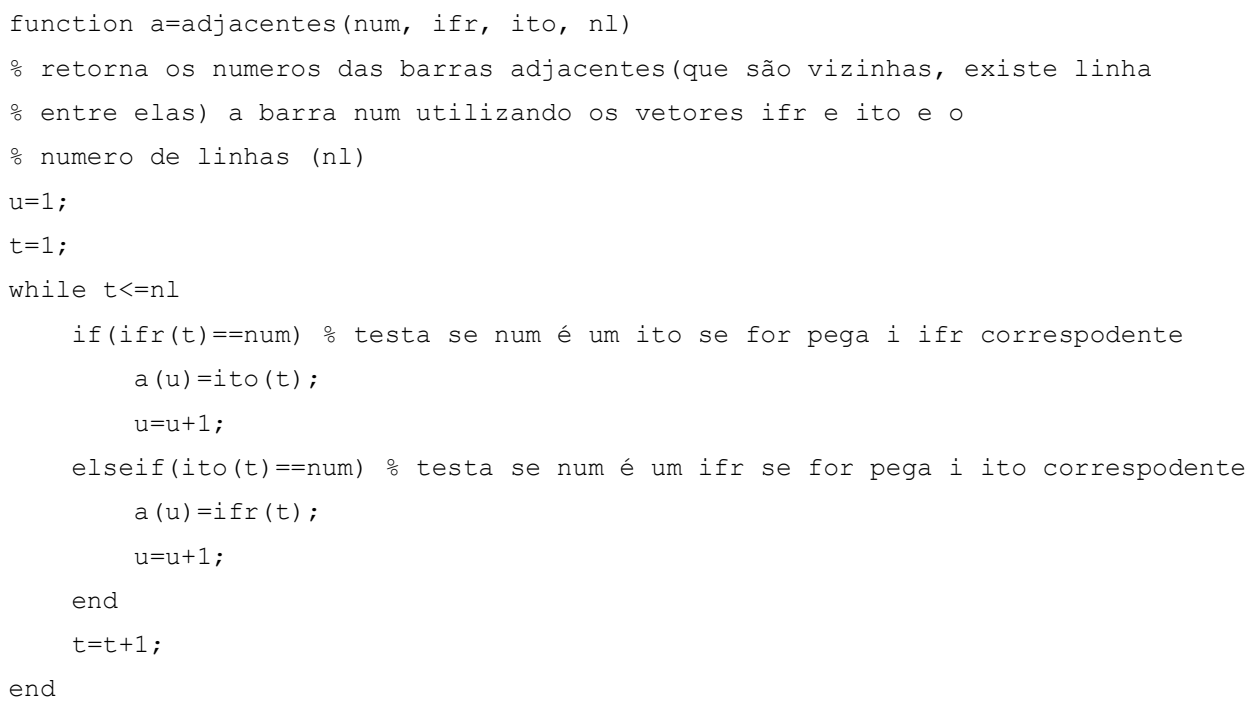

- Função pflowji:

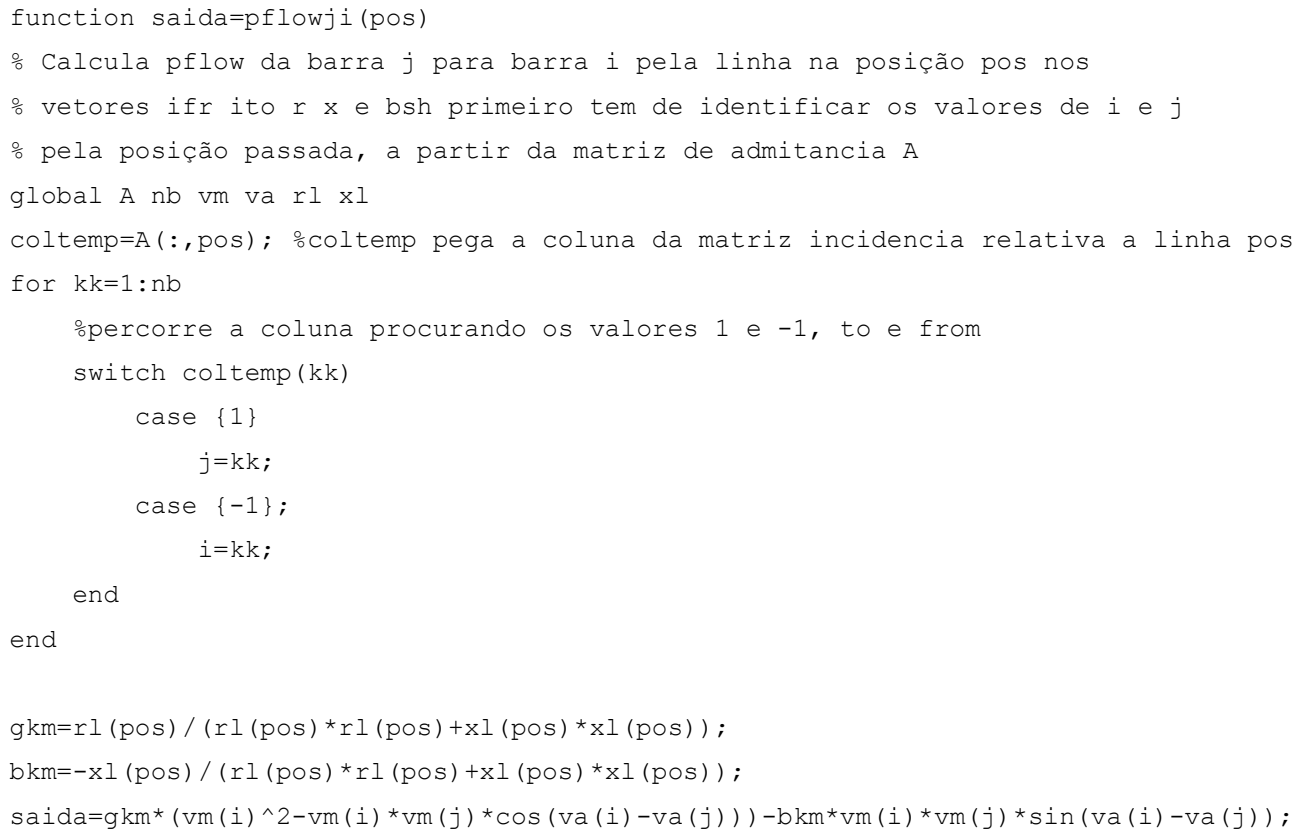

- Função pflowij:

function saida=pflowij (pos) 


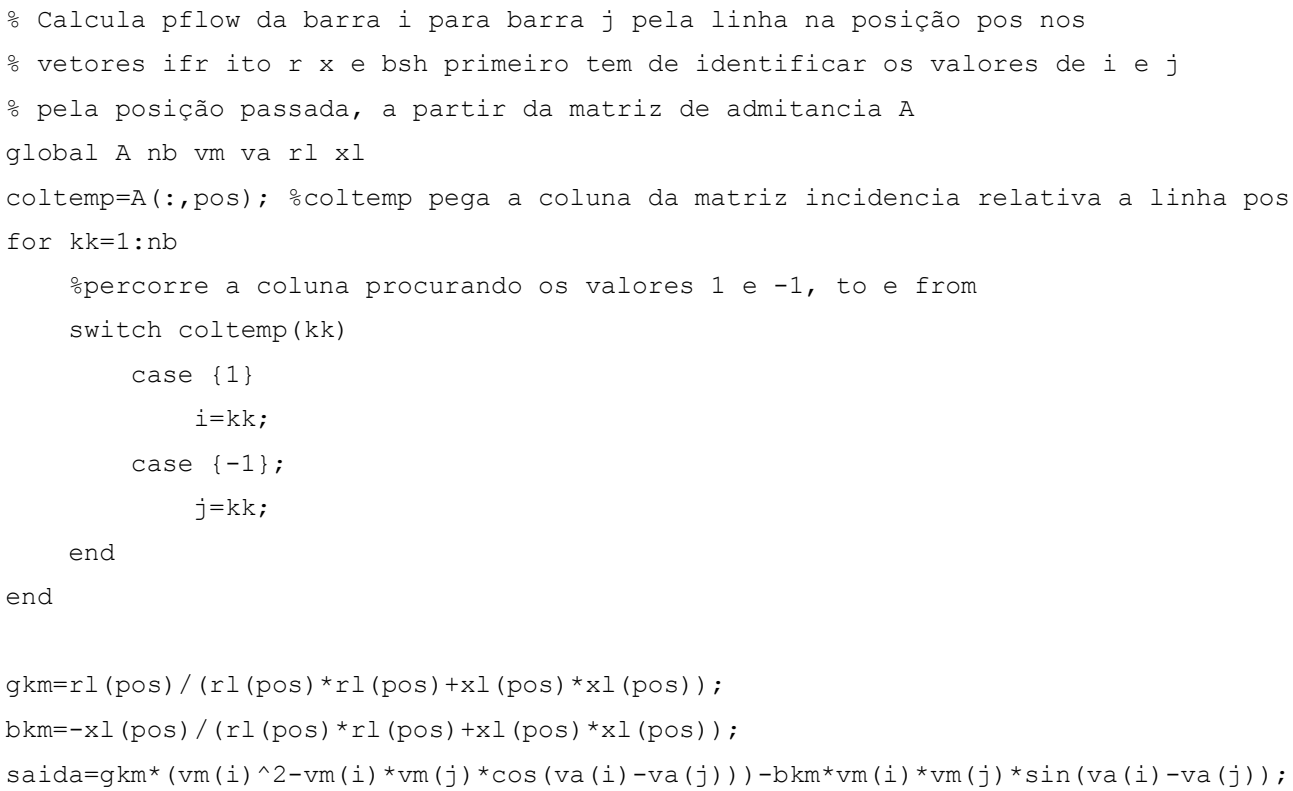

\section{- Função peganumlinha:}

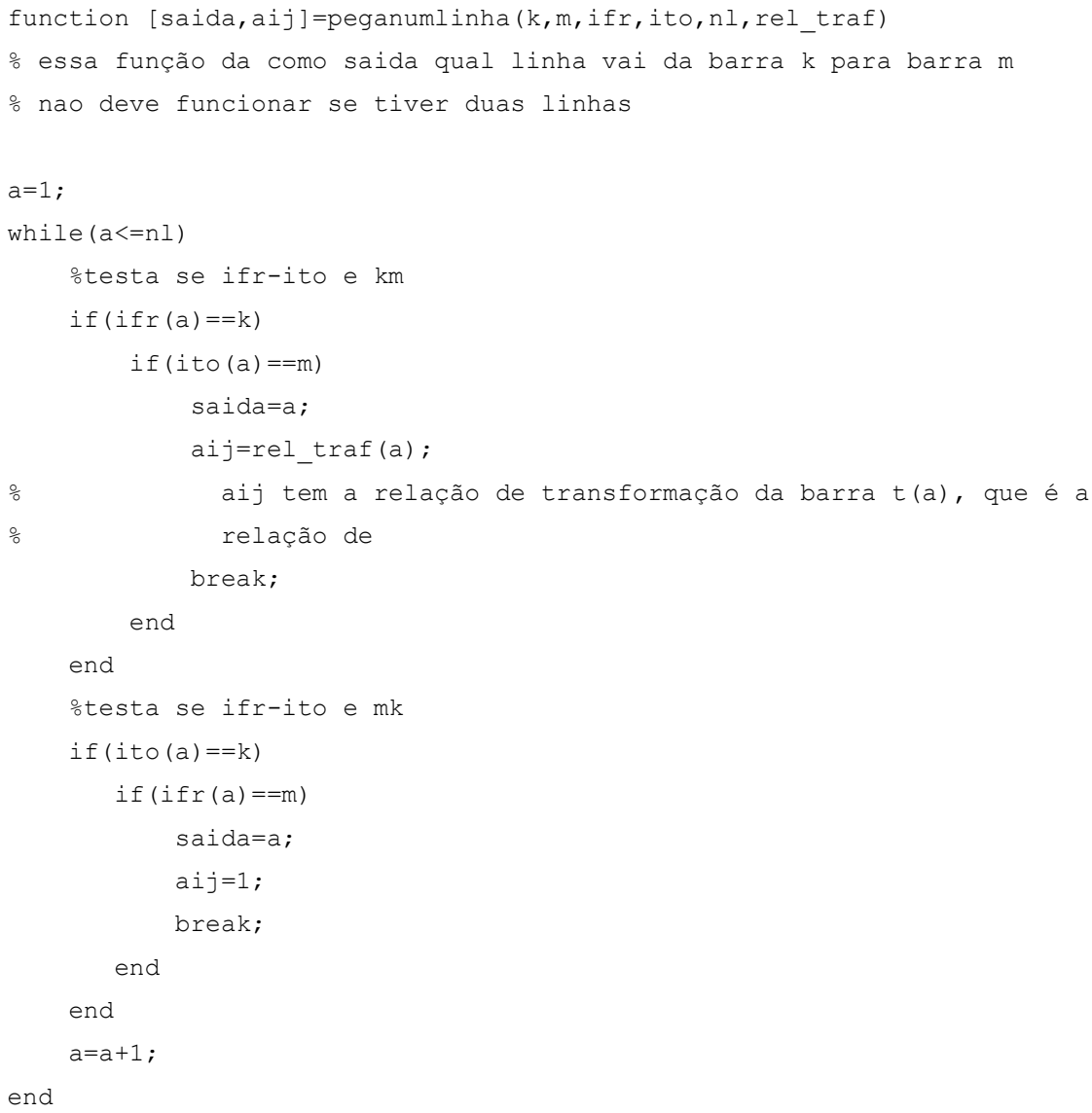

